\title{
Genome Sequencing of Ciboria shiraiana Provides Insights into the Pathogenic Mechanisms of Hypertrophy Sorosis Scleroteniosis
}

\author{
Panpan Zhu, ${ }^{1,2}$ Min Kou, ${ }^{1}$ Changying Liu, ${ }^{1}$ Shuai Zhang, ${ }^{1}$ Ruihua Lü, ${ }^{1,3}$ Zhongqiang Xia, ${ }^{1}$ Maode Yu, \\ and Aichun Zhao ${ }^{1,+}$ \\ ${ }^{1}$ The State Key Laboratory of Silkworm Genome Biology, College of Biotechnology, Southwest University, Chongqing, China \\ ${ }^{2}$ Key Laboratory of Biorheological Science and Technology, Ministry of Education, Chongqing University, Chongqing, China \\ ${ }^{3}$ College of Medical Technology, Shanxi University of Chinese Medicine, Xianyang, Shanxi Province, China
}

Accepted 30 September 2020.

\begin{abstract}
Ciboria shiraiana causes hypertrophy sorosis scleroteniosis in mulberry trees, resulting in huge economic losses, and exploring its pathogenic mechanism at a genomic level is important for developing new control methods. Here, genome sequencing of C. shiraiana based on PacBio RSII and Illumina HiSeq 2500 platform as well as manual gap filling was performed. Synteny analysis with Sclerotinia sclerotiorum revealed 16 putative chromosomes corresponding to 16 chromosomes of $C$. shiraiana. Screening of rapid-evolution genes revealed that 97 and $2.4 \%$ of genes had undergone purifying selection and positive selection, respectively. When compared with $S$. sclerotiorum, fewer secreted effector proteins were found in $C$. shiraiana. The number of genes involved in pathogenicity, including secondary metabolites, carbohydrate active enzymes, and $\mathbf{P 4 5 0}$ s, in the $C$. shiraiana genome was comparable with that of other necrotrophs but higher than that of biotrophs and saprotrophs. The growth-related genes and plant cell-wall-degradation-related genes in $C$. shiraiana were expressed in different developmental and infection stages, and may be potential targets for prevention and control of this pathogen. These results provide new insights into $C$. shiraiana pathogenic mechanisms, especially host range and necrotrophy features, and lay the foundation for further study of the underlying molecular mechanisms.
\end{abstract}

The Whole Genome Shotgun Project has been deposited at DNA Data Bank of Japan/European Nucleotide Archive/GenBank under accession number VNFM00000000. The version described in this article is VNFM01000000.

P. Zhu and M. Kou contributed equally to this work.

${ }^{\dagger}$ Corresponding author: A. Zhao; zhaoaichun@ hotmail.com

Funding: This work was supported by grants from the National Key R\&D Program of China (number 2019YFD1000604) and China Agriculture Research System (number CARS-18-ZJ0201) and the National Science Foundation of Chongqing (grant number cstc2019jcyj-bsh0106).

*The $\boldsymbol{e}$-Xtra logo stands for "electronic extra" and indicates that supplementary materials are published online.

The author(s) declare no conflict of interest.

(0) PUBLIC

The author(s) have dedicated the work to the public domain under the Creative Commons CCO "No Rights Reserved" license by waiving all of his or her rights to the work worldwide under copyright law, including all related and neighboring rights, to the extent allowed by law.
Keywords: Ciboria shiraiana, fungal development, genome, genomics, mechanisms of pathogenicity, metabolomics, mulberry, pathogenicity, plant cell wall-degrading enzymes, proteomics

Ciboria shiraiana is a plant-pathogenic fungus belonging to the genus Ciboria of the Sclerotiniaceae family. Owing to their wide host range, pathogens from the Sclerotiniaceae family cause devastating plant diseases worldwide, leading to huge economic losses each year. For instance, Botrytis cinerea invades more than 200 crop hosts worldwide and causes massive losses in crops prior to harvest or even at the seedling stage of some hosts (Williamson et al. 2007). The annual losses caused by Sclerotinia sclerotiorum in the United States have exceeded \$200 million (Bolton et al. 2006). However, to date, other than chemical fungicides, there are no efficient methods to control these plant pathogens. Analysis of the pathogenic mechanism of these fungi at the genomic level is crucial to develop novel control strategies. In 2011, comparative genomic analysis of two necrotrophic fungi ( $B$. cinerea and $S$. sclerotiorum) shed light on the evolutionary and mechanistic bases of genetically complex traits of necrotrophic pathogenicity (Amselem et al. 2011). Genome sequencing of these two pathogenic fungi helped researchers gain insights into genes involved in fungal development, including 245 sclerotia production-associated orthologs and 15 conidiationrelated orthologous gene pairs shared by $S$. sclerotiorum and $B$. cinerea, which could be used as antifungal drug targets. Necrotrophs are defined as pathogens that first kill host plant cells and then derive nutrients from killed host cells (Pieterse et al. 2009).

To acquire nutrition from the host, necrotrophic pathogens break through cuticles and plant cell walls and secrete cellwall-degrading enzymes (CWDEs) and secondary metabolites (SMs) such as toxins to promote decomposition of the cuticle and plant cell wall (Blanc et al. 2018; Kars et al. 2005; Thomma 2003; Toth et al. 2003). When pathogens break through the cuticle and plant cell wall, cuticular and plant cell wall fragments induce danger-associated molecular patterns, and pathogen-associated molecular patterns (PAMPs) are released and recognized by pattern recognition receptors (Boller and Felix 2009). This is the first line of defense in plants and is named PAMP-triggered immunity (PTI), and the effectors secreted by the pathogens are recognized by intracellular receptors and induce effector-triggered immunity (ETI) (Dodds and Rathjen 2010). In general, PTI acts against nonadapted 
pathogens, whereas ETI has been shown to increase pathogen toxicity or inhibit host immune responses (Bos et al. 2006; Dou et al. 2008; Ridout et al. 2006; Sohn et al. 2007).

Mulberry fruit scleroteniosis is a fungal disease and was first reported by Siegler and Jenkins (1922). Three types of scleroteniosis have been identified; namely, hypertrophy sorosis scleroteniosis, reduced sorosis scleroteniosis, and pellet sorosis scleroteniosis, caused by $C$. shiraiana, Scleromitrula shiraiana, and C. carunculoides, respectively (Kishi 1998; Kohn and Nagasawa 1984; Whetzel and Wolf 1945). In China, C. shiraiana causes the most serious scleroteniosis as a typical epidemic disease during mulberry fruit growth. Three factors have been found to cause hypertrophy sorosis scleroteniosis, leading to severe damage, seriously threatening the production of mulberry fruit, and, thus, restricting the development of the mulberry industry. First, the germination time of pathogenic sclerotia is from January to April, which exactly covers the flowering period of the existing mulberry fruit varieties. Second, the ascospores of $C$. shiraiana infect female mulberry flowers, causing an initial infection, and the conidiospores spread from diseased fruit to healthy fruit, causing secondary infection because mulberry is an aggregate fruit (Lü et al. 2019).

Although C. shiraiana has been reported in the fields many times in China, studies of its molecular pathogenesis are still very limited (Kuai and Wu 2012; Wang 2003, 2009). Furthermore, owing to the lack of genomic information, it is extremely difficult to conduct molecular studies and functional characterization of genes in $C$. shiraiana. In this study, we determined the genome of the pathogenic fungus $C$. shiraiana by sequencing, assembling, and annotating. To investigate the pathogenic mechanisms of $C$. shiraiana, a comparative genomics study with two related necrotrophic fungi, one biotrophic fungus, and two saprobic fungi was also conducted. This study is the first to conduct high-quality genome sequencing of C. shiraiana and is also the first to report on the genome of the pathogen causing mulberry fruit scleroteniosis. The findings of this study may serve as a model for investigating the pathogenic mechanisms in mulberry fruit, and also complement and validate the pathogenesis of necrotrophic pathogens. In addition, the present study will provide knowledge for improving mulberry fruit yield in sericulture and also offer a scientific basis for research and development of antifungal drug targets and biological control methods.

\section{RESULTS}

\section{General genomic features.}

In total, $6.7 \mathrm{~Gb}$ of raw sequences were generated from the Illumina HiSeq 2500 platform, representing 180x high coverage, and $4.7 \mathrm{~Gb}$ of raw sequences were generated from PacBio RSII platform (Table 1). The long reads of PacBio were assembled de novo and the short reads of Illumina were mapped to the assembled genome sequences to create a consensus sequence. To generate a more complete and accurate genome for $C$. shiraiana, we used the first-generation sequencing Sanger method to repair the gap between the short scaffolds (Supplementary Table S2).

The final assembly size of the $C$. shiraiana genome was noted to be $39.2 \mathrm{Mb}$, which was assembled into 23 scaffolds. The genome size of $C$. shiraiana was found to be similar to its closely related fungi Sclerotinia sclerotiorum $(38.3 \mathrm{Mb})$ and $B$. cinerea $(39.5 \mathrm{Mb})$, indicating that genome size is conserved among these three fungi (Amselem et al. 2011). The GC content of the C. shiraiana genome sequence $(41.6 \%)$ was comparable with that of S. sclerotiorum (41.8\%) but significantly lower than that of Pyronema omphalodes $(47.8 \%$,
Pezizomycotina). Unlike most of the other members of class Pezizomycetes (50 to 52\%), class Leotiomycetes has been reported to have a relatively low GC content, which may affect the chromosome organization and stable transcription level (Leroch et al. 2011). In total, 14,439 protein-coding genes were predicted in this study, and the other assembly statistics of the genome are summarized in Table 1 and Supplementary Table S3.

\section{Improvement in assembly level via synteny analysis with $S$. sclerotiorum.}

To assemble the genome of $C$. shiraiana at the chromosome level, we used the 16 chromosome sequences of $S$. sclerotiorum as the reference sequence and aligned the 23 scaffolds of C. shiraiana to the reference sequence for synteny analysis (Fig. 1A; Supplementary Fig. S1). In total, 97 and $96 \%$ of the $C$. shiraiana genome could be aligned to the $S$. sclerotiorum genome at the nucleotide level and protein level, respectively. The large synteny regions shared by these two fungi indicate that $C$. shiraiana adequately retained the progenitor genomic features before divergence from $S$. sclerotiorum. Meanwhile, some rearrangement events were also noted in the $C$. shiraiana genome. The synteny analysis consisted of 16 putative chromosomes, corresponding to the 16 chromosomes of $C$. shiraiana, as observed under the microscope (Fig. 1B and C). Among the 16 putative chromosomes, 8 scaffolds were found to correspond to one chromosome, while the rest exhibited one-to-one correspondence (Supplementary Table S4). These eight scaffolds failed to accomplish gap filling via Sanger assembly owing to repeat sequences.

\section{Genome annotation.}

The average gene length was $1,211 \mathrm{bp}$, and 368 genes were spaced at every $1 \mathrm{Mb}$ of the genome, which indicated that the gene density of $C$. shiraiana is similar to that of many other fungi. Only 5,956 (41.25\%), 7,480 (51.80\%), 10,817 $(74.92 \%)$, and $14,135(97.89 \%)$ of the predicted genes presented homologies with known functions in the Cluster of Orthologous Groups of proteins, SwissProt, Kyoto Encyclopedia of Genes and Genomes, and nonredundant protein (nr) databases, respectively (Supplementary Table S3). With regard to noncoding genes, we identified 213 transfer RNA (tRNA) and 99 ribosomal RNA (rRNA) from the assembly (Supplementary Table S5). In the present study, repetitive sequences were identified by RepeatMasker, which revealed $12.54 \%$ of the $C$. shiraiana genome as repeats, with almost all the repeats being transposable elements (TEs). The TEs

Table 1. Assembly statistics of Ciboria shiraiana genome

\begin{tabular}{lccc}
\hline Parameters & $\begin{array}{c}\text { Illumina } \\
\text { HiSeq 2500 }\end{array}$ & $\begin{array}{c}\text { PacBio } \\
\text { RSII }\end{array}$ & $\begin{array}{c}\text { Integration } \\
\text { statistics }^{\mathbf{b}}\end{array}$ \\
\hline Scaffold $(\mathrm{N})$ & 1,531 & 29 & 23 \\
Total length $(\mathrm{Mb})$ & 37 & 39.2 & 39.2 \\
Gap (bp) & 497,283 & 0 & $\mathrm{NA}$ \\
$\mathrm{N}_{50}$ length (bp) & 59,408 & $2,416,698$ & $\mathrm{NA}$ \\
$\mathrm{N}_{90}$ length (bp) & 14,564 & $1,835,576$ & $\mathrm{NA}$ \\
Coverage & $180 \times$ & $120 \times$ & NA \\
GC content $(\%)$ & 41.73 & 41.63 & NA \\
Gene number $(\mathrm{N})$ & $\mathrm{NA}$ & $\mathrm{NA}$ & 14,439 \\
Average gene length (bp) & $\mathrm{NA}$ & $\mathrm{NA}$ & 1,211 \\
Gene GC content $(\%)$ & $\mathrm{NA}$ & $\mathrm{NA}$ & 45.67 \\
\hline
\end{tabular}

a NA denotes not available.

b Integration statistics represents the result of the integration of Illumina HiSeq 2500, PacBio RSII, and Sanger assembly statistics. 
identified in the $C$. shiraiana genome were grouped into families and annotated as class I (LTR and LINE) and unknown TEs, whereas class II TEs (MITE and TIR) were absent. Among them, unknown TEs accounted for $5.36 \%$ of the $C$. shiraiana genome. The proportion of TEs in the $C$. shiraiana genome was found to be comparable with that in the $S$. sclerotiorum genome (10\%) (Amselem et al. 2011) but significantly lower than that in the Blumeria graminis genome (Supplementary Table S6).

\section{Analysis of the gene family.}

To identify the gene family of the six fungi, 36,819 genes were grouped into 8,965 clusters. Among these clusters, 1,196 gene families were identified as single-copy gene families (data not shown). In total, 3,083 common gene families were noted among the five fungi (Fig. 2). In addition, $C$. shiraiana and $S$. sclerotiorum were also found to share the most common gene families when compared with other fungal species, which further supported the results of phylogenetic tree analysis.

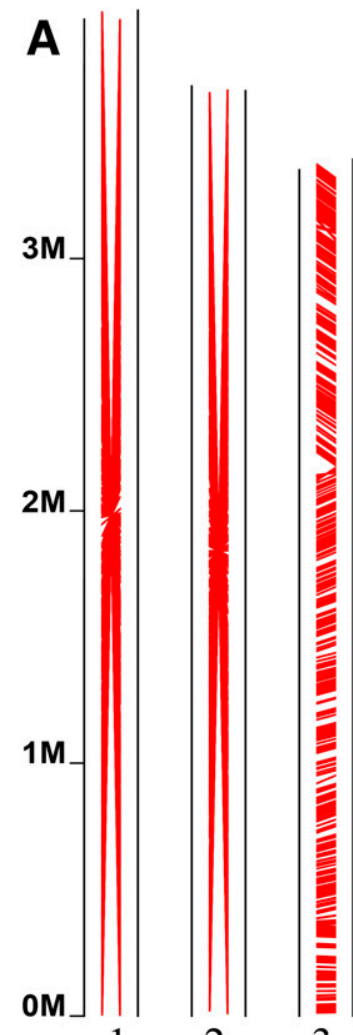

1

2

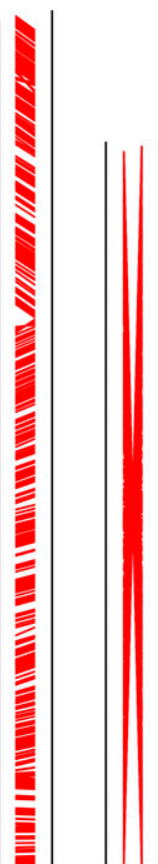

4

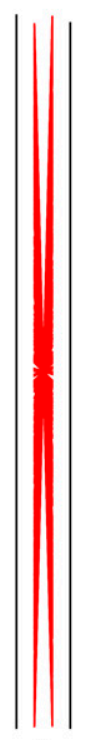

5

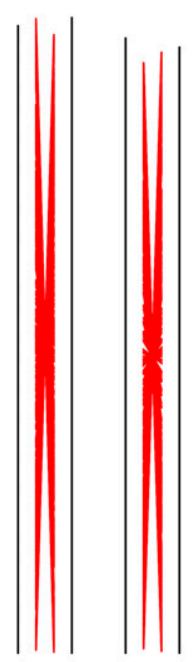

6
7

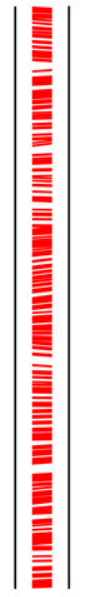

8

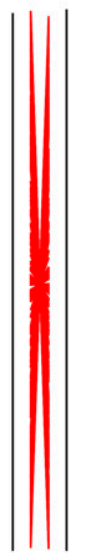

9

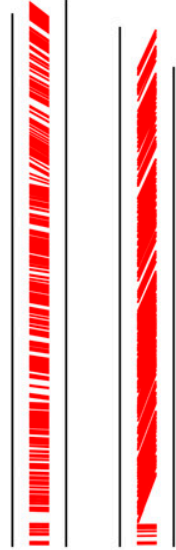

11

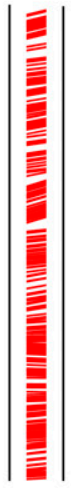

12

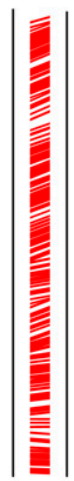

13

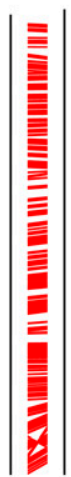

14
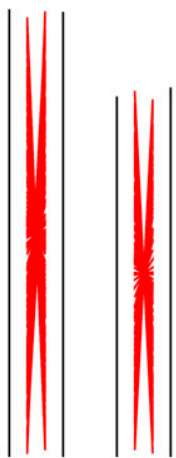

$15 \quad 16$

\section{C}
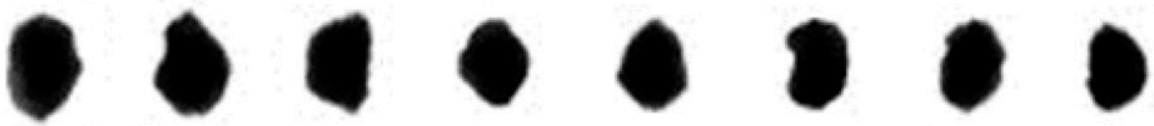

B

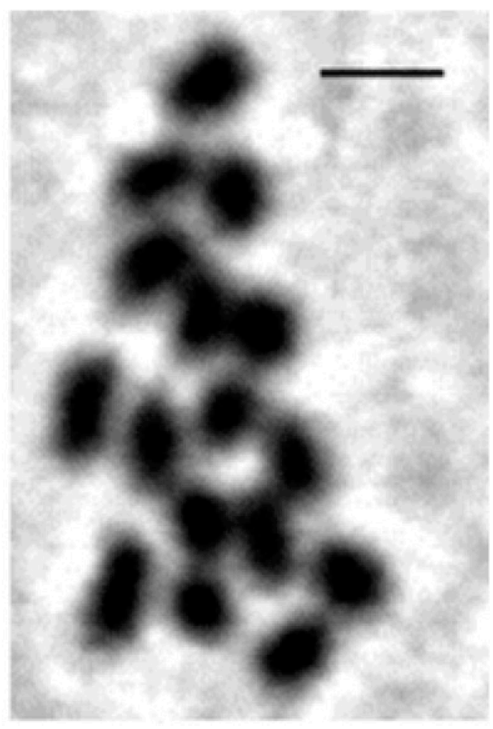

Fig. 1. Synteny analysis with Sclerotinia sclerotiorum and karyotype of Ciboria shiraiana. A, Synteny analysis with S. sclerotiorum. The S. sclerotiorum chromosome as reference sequence is shown on the left (black line), scaffold of $C$. shiraiana is shown on the right (black line), and syntenic regions are shown in red. B, Shape and size of each chromosome. $\mathbf{C}$, Number of chromosomes observed under the microscope. Bar $=5 \mu \mathrm{m}$. 
C. shiraiana contains 74 specific gene families, including 189 genes, of which 99 genes were enriched in the cellular process and 15 genes were enriched in metabolic pathways, and these unique genes can be explored as a potential target to affect the metabolism and pathogenicity of $C$. shiraiana (Supplementary Fig. S2).

The gain and loss of genes is one of the major contributors to functional changes ( $\mathrm{Li}$ et al. 2010). In total, 435 gene families consisting of 2,460 genes were found to be expanded (more than one copy of the gene) in the $C$. shiraiana genome (Supplementary Fig. S3). Among these expanded gene families, 138 genes were enriched in binding and seven genes were enriched in metabolic pathways (Supplementary Fig. S4). Meanwhile, 1,045 gene families were noted to be contracted, and their proportion was higher than gene expansion in the six fungal genomes examined, indicating that loss-of-function might play an important role in functional evolution.

\section{Pairwise gene nonsynonymous/synonymous sites.}

The diverse environments and hosts in which various fungi exist may reflect different selections on orthologous genes. A high pairwise nonsynonymous/synonymous $(\mathrm{Ka} / \mathrm{Ks})$ value suggests that the protein rapidly evolved in the species. The evolution rate can be revealed by the footprints of past positive selection, which is measured as the rate of nonsynonymous nucleotide substitution per nonsynonymous site $(\mathrm{Ka})$ relative to the underlying neutral mutation rate, given by the rate of synonymous nucleotide substitution per synonymous site (Ks) (Hurst 2002; Navarro and Barton 2003). To analyze the $\mathrm{Ka} / \mathrm{Ks}$ nucleotide substitution rate ratio, we estimated that 1,976, 126, 22, 48, and 47 gene pairs have significantly higher neutral $\mathrm{Ka} / \mathrm{Ks}$ nucleotide substitution rate ratios $(\mathrm{Ka} / \mathrm{Ks}=$ 1 ), indicating positive selections for $C$. shiraiana-S. sclerotiorum, $C$. shiraiana-S. borealis, $C$. shiraiana-B. graminis, $C$. shiraiana$P$. omphalodes, and C. shiraiana-Saccharomyces cerevisiae, respectively (data not shown). In total, 119,218 gene pairs were used

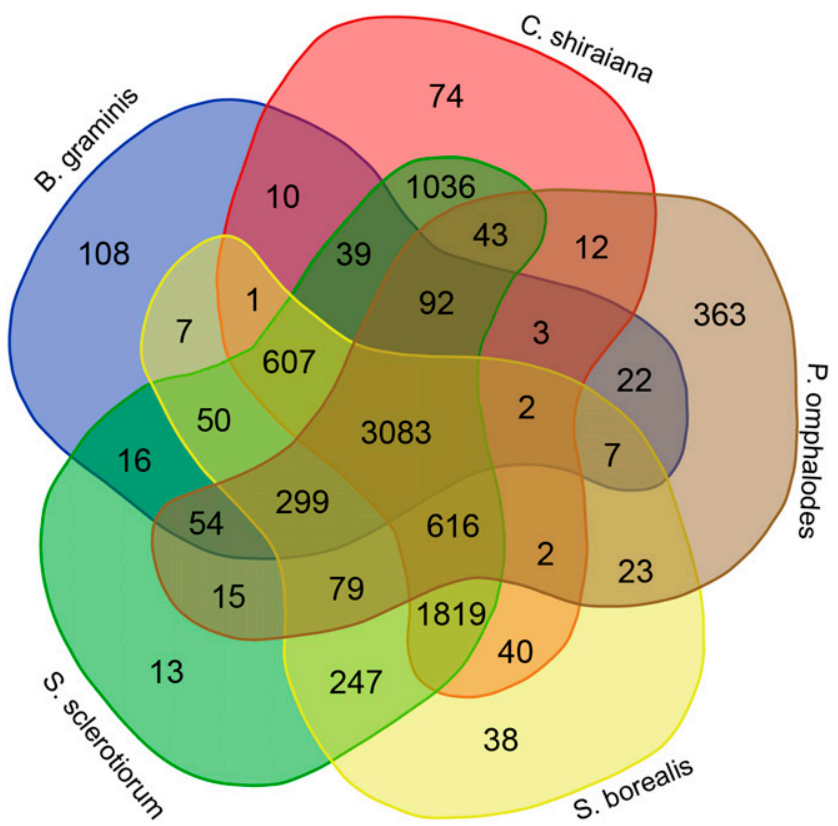

Fig. 2. Common and specific gene families among the five fungi. The Venn diagram was used to compare the common gene families and specific gene families of the five fungi. The five colors indicate five species (red = Ciboria shiraiana, purple $=$ Pyronema omphalodes, yellow = Sclerotinia borealis, green $=S$. sclerotiorum, and blue $=$ Blumeria graminis $)$, and the overlap parts have overlapping color. Numbers in the overlap parts indicate common gene families and nonoverlap parts denote specific gene families in each comparison. to identify nucleotide substitution events. Among these gene pairs, $97 \%$ were considered to have undergone purifying selections, while only $2.4 \%$ were presumed to have undergone positive selections.

\section{Secreted effector proteins.}

In the present study, we first filtered the prediction of secreted proteins using SignalP to identify 738 proteins with a secretion signal. Next, 738 proteins were predicted by TMHMM to harbor transmembrane helices, and 149 proteins were identified using TargetP v1.1 to remove predicted signal peptide related to organelles. Finally, 120 proteins were predicted by PredGPI to harbor glycophosphatidylinositol anchor motifs, which mostly represent membrane proteins rather than secreted effectors. In addition, we predicted six candidates of small secreted effector proteins, which were small (76 to 300 amino acids), secreted (signal peptide), and rich in cysteine (3\%) when compared with other genes encoding proteins from the genome of $C$. shiraiana. One of these proteins was noted to contain a cell wall stress-responsive component domain, while the rest of the predicted small secreted effector proteins did not contain any known PFAM domains (data not shown).

\section{Carbohydrate active enzymes annotation.}

The ability to decompose plant carbohydrates is an important characteristic of necrotrophic fungal lifestyle. Plant cell wall carbohydrates are composed of a complex network of different polysaccharides that are segmented into three categories: cellulose, hemicellulose, and pectin. Carbohydrate active enzymes (CAZymes) are proteins involved in the degradation of plant biomass and conversion to fungal mass (van Kan 2006). In total, 400 CAZyme-coding gene homologs were determined using the domain-based annotation dbCAN in combination with CAT in the genome of $C$. shiraiana, which comprised 244 glycoside hydrolases (GHs), 7 polysaccharide lyases (PLs), 35 carbohydrate esterases (CEs), 99 glycosyl transferases (GTs), and 15 carbohydrate-binding modules (CBMs) (Table 2). The former three types of CAZymes are often known as CWDEs because they play a central role in the decomposition of plant cell walls by fungi. GHs are the most abundant CAZymes and the majority of them are related to hemicellulose or pectin decomposition (Yang et al. 2016). In the present study, the CAZymes of the other five fungi were also examined, and the number of CAZymes in three necrotrophic fungi was noted to be significantly higher than that in the biotrophic fungus $B$. graminis as well as the two nonpathogenic fungi $P$. omphalodes and S. cerevisiae (Table 2).

\section{P450 annotation.}

Cytochrome P450 enzymes belong to a group of structurally conserved but functionally diverse heme-containing mixedfunction oxidases distributed in different life forms, including

Table 2. Comparison of carbohydrate active enzymes between Ciboria shiraiana and other five Ascomycetes with different lifestyles ${ }^{\mathrm{a}}$

\begin{tabular}{|c|c|c|c|c|c|c|c|}
\hline Fungal species & Lifestyle & GHs & CBMs & CEs & GTs & PLs & Total \\
\hline C. shiraiana & Necrotroph & 244 & 15 & 35 & 99 & 7 & 400 \\
\hline $\begin{array}{l}\text { Sclerotinia } \\
\text { sclerotiorum }\end{array}$ & Necrotroph & 241 & 16 & 41 & 102 & 5 & 405 \\
\hline S. borealis & Necrotroph & 217 & 17 & 33 & 100 & 8 & 375 \\
\hline Botrytis graminis & Biotroph & 75 & 5 & 15 & 63 & 0 & 158 \\
\hline P. omphalodes & Saprotroph & 129 & 15 & 28 & 67 & 5 & 244 \\
\hline S. cerevisiae & Saprotroph & 52 & 9 & 4 & 71 & 0 & 136 \\
\hline
\end{tabular}

a Values reflect the total number of members in the families. GHs = glycoside hydrolases, $\mathrm{CBMs}=$ carbohydrate-binding modules, CEs = carbohydrate esterases, GTs = glycosyl transferases, and PLs = polysaccharide lyases. 
prokaryotes and eukaryotes (van den Brink et al. 1998). In the present study, based on online database and multiple rigorous screening, 77 genes were identified as P450s in the C. shiraiana genome, which is similar to those in the other two fungi that are from the family Sclerotiniaceae; namely, Sclerotinia sclerotiorum (87 genes) and $S$. borealis ( 78 genes), slightly higher than those in $B$. graminis (52 genes) and $P$. omphalodes (51 genes), and significantly higher than those in Saccharomyces cerevisiae (5 genes) (Fig. 3).

\section{Secondary metabolism.}

Necrotrophic pathogens kill the host cells by producing a diverse array of SMs, including peptides, polyketides, terpenes, and alkaloids, which are synthesized by NRPS, PKS, terpene synthase, and dimethylallyl tryptophane synthases, respectively. In most fungi, genes involved in the biosynthesis of SMs are generally clustered together, and a classical gene cluster contains genes encoding the signature enzymes that synthesize the skeletons of different classes of SMs as well as genes encoding the tailoring enzymes that modify the skeletons. In the present study, $C$. shiraiana genome was found to be enriched with NRPS, PKS, and diterpene cyclase. In total, 23 SM clusters, including 25 key SM enzyme genes, were identified using the antiSMASH software, and these clusters were observed to be evenly distributed across the $C$. shiraiana genome (Table 3). The number of key enzyme genes in C. shiraiana was determined to be similar to that in the other two necrotrophic fungi examined but was significantly higher than that in the Leotiomycete $B$. graminis, whose obligate biotrophic lifestyle caused numerous gene losses (Spanu et al. 2010; Wicker et al. 2013).

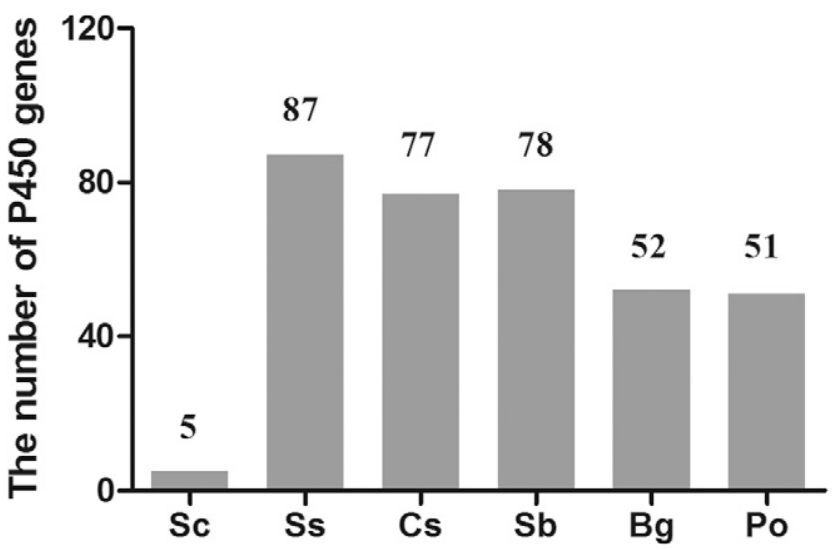

Fig. 3. Distribution of $\mathrm{P} 450$ gene in the six fungi examined. The $x$ axis shows the name of six fungi $(\mathrm{Sc}=$ Sclerotinia cerevisiae, $\mathrm{Ss}=S$. sclerotiorum, $\mathrm{Cs}=$ Ciboria shiraiana, $\mathrm{Sb}=$ Sclerotinia borealis, $\mathrm{Bg}=$ Blumeria graminis, and $\mathrm{Po}=$ Pyronema omphalodes). The $y$ axis shows the number of P450 genes.

Table 3. Number of secondary metabolism biosynthetic genes in four fungi ${ }^{\mathrm{a}}$

\begin{tabular}{|c|c|c|c|c|c|c|c|}
\hline Species & PKS & NRPS & CHS & DMATS & STC & DTC & $\begin{array}{l}\text { NRPS- } \\
\text { PKS }\end{array}$ \\
\hline $\begin{array}{l}\text { Ciboria } \\
\text { shiraiana }\end{array}$ & 9 & 10 & 1 & 1 & 0 & 3 & 1 \\
\hline Botrytis cinerea & 16 & 9 & 1 & 1 & 6 & 3 & 5 \\
\hline $\begin{array}{l}\text { Sclerotinia } \\
\text { sclerotiorum }\end{array}$ & 15 & 6 & 1 & 1 & 0 & 1 & 1 \\
\hline B. graminis & 1 & 1 & 1 & 0 & 0 & 0 & 0 \\
\hline
\end{tabular}

\section{Transcription factors.}

Transcription factors (TFs) play a vital role in regulatory networks by acting as a linker between signal flow and target gene expression. Approximately 290 protein sequences (2\% of total genes) were found to encode five main different classes of TFs in C. shiraiana. Among the five classes of TFs, Cys6 (124 genes) was found to be predominantly distributed, followed by $\mathrm{C}_{2} \mathrm{H}_{2}$ (61 genes), bZIP (15 genes), GATA (10 genes), and bHLH (6 genes) (Table 4). The number of Cys6 TFs was determined to be comparable with that in other Ascomycetes (Sclerotinia sclerotiorum, $n=155$, and Botrytis cinerea, $n=$ 222) because Cys6 TFs participate in many biological functions such as sugar and amino acid metabolism, gluconeogenesis, and respiration. Another major class of TFs in $C$. shiraiana is $\mathrm{C}_{2} \mathrm{H}_{2}$ (approximately 61 genes), which is known to be involved in growth, development, and virulence of the plant pathogen (Kim et al. 2009; Schumacher et al. 2008). In addition, 15 genes encoding bZIP TFs were detected in C. shiraiana (Table 4). In previous studies on Magnaporthe oryzae, deletion mutants of bZIP TFs Moatf1 and MoAP1 were reported to show $\mathrm{H}_{2} \mathrm{O}_{2}$ sensitivity, various defects in aerial hyphal growth, and conidia formation, suggesting that this class of TFs is necessary for complete virulence of M. oryzae (Guo et al. 2010, 2011). Therefore, it would be of interest to characterize the regulatory networks controlled by these TFs in C. shiraiana.

\section{Analysis of growth-related genes.}

Sclerotia are dormant structures that could remain viable for up to 8 years in soil (Young and Ashford 1992). In southwest China, sclerotia revive from dormancy from January until April, which coincides with the entire blossom period of mulberry trees. In fungi, the MADS-box gene has been found to be involved in growth, sclerotia production, and pathogenicity of $B$. cinerea (Zhang et al. 2016). In the present study, the predicted gene Cs11201 was observed to be orthologous to SsMADS, with 99\% identity at the nucleotide level (Supplementary Table S7). Detection of the transcript levels of Cs11201 via quantitative real-time reverse-transcription PCR (qRT-PCR) showed that Cs11201 is transcriptionally induced during sclerotial development stages, implying that Cs11201 may be involved in sclerotia development (Fig. 4A).

When sclerotia break dormancy, apothecia germinate. One sclerotium could contain 1 to 15 germinating apothecia, and the number of ascospores in a 1.5 -cm-diameter apothecia can reach up to $5.6 \times 10^{7}$ to $6.3 \times 10^{7}$, which is a significantly high inoculum potential (Lü et al. 2019). Genes involved in the formation of apothecia in other fungi include genes encoding the Forkheadbox TF Ss-FoxE2 (Wang et al. 2016), tactin-bundling protein FgFim (Zheng et al. 2014), GATA-type IVb zinc-finger TF $S s N s d l$ (Li et al. 2018), and endo- $\beta-1,4-x y l a n a s e ~ S s X y l-1$ (Yu et al. 2016). In the present study, orthologs of these apothecia formation-associated genes were detected in the C. shiraiana genome. The qRT-PCR results showed that Cs13232 and Cs04366 exhibited an increased transcription level in

Table 4. Number of transcription factors (TFs) in Ciboria shiraiana and other two Ascomycetes

\begin{tabular}{lccc}
\hline TF types & Sclerotinia sclerotiorum & Botrytis cinerea & C. shiraiana \\
\hline Cys6 & 155 & 222 & 124 \\
$\mathrm{C}_{2} \mathrm{H}_{2}$ & 98 & 116 & 61 \\
bHLH & 9 & 9 & 6 \\
bZIP & 25 & 25 & 15 \\
GATA & 9 & 8 & 10 \\
Total & 296 & 380 & 216 \\
\hline
\end{tabular}


sclerotia3, while Cs04365 and Cs02399 presented a higher transcription level in conidia (Fig. 4B to E).

A number of genes are crucial for the virulence of pathogenic fungi, including Bc-Mtg2 (Shao et al. 2016), Ss-Ggtl (Li et al.
2012), Fg-Fim (Zheng et al. 2014), Ss-Nsdl (Li et al. 2018), and Ss-oahl (Liang et al. 2015), and the orthologs of these pathogenicity-associated genes were found in the genome of C. shiraiana (Supplementary Table S7). Detection of the
A
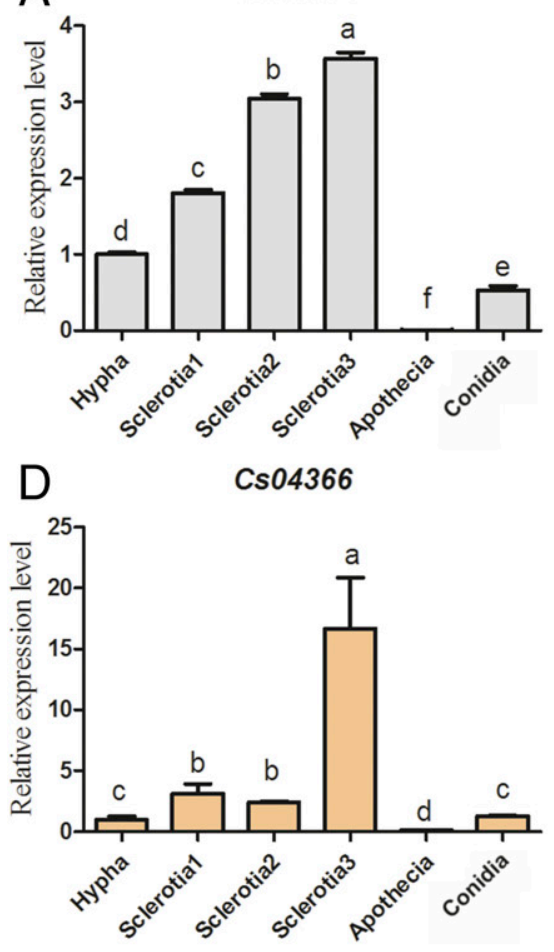

G

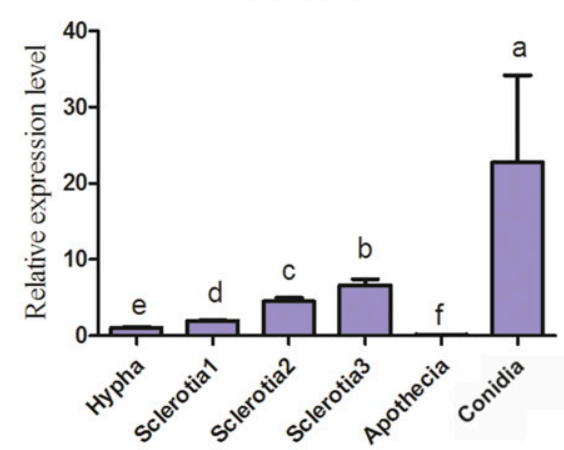

J

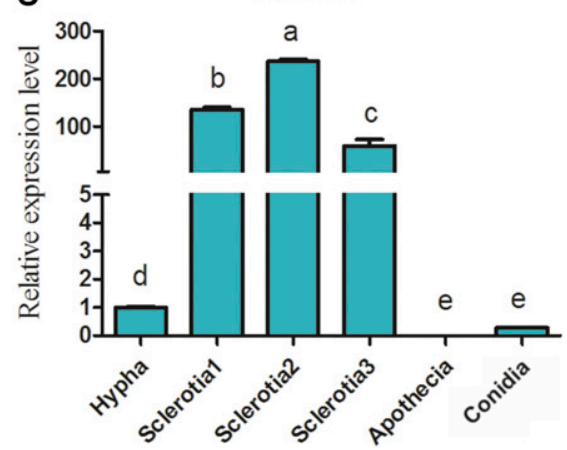

B

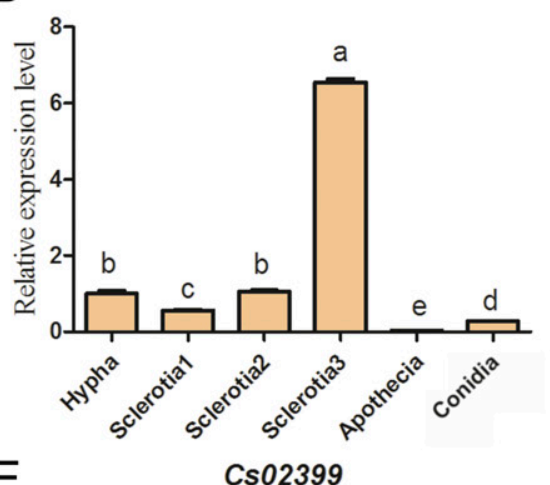

E

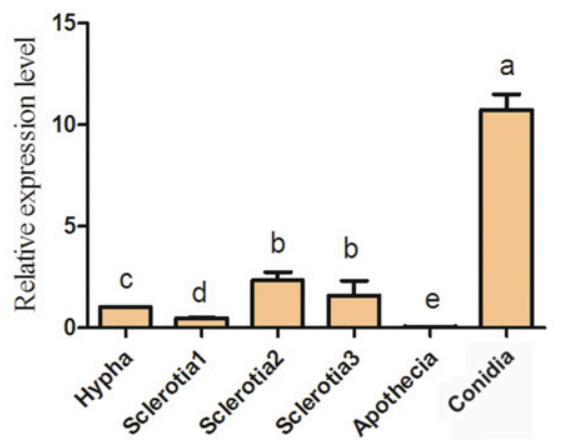

$\mathrm{H}$

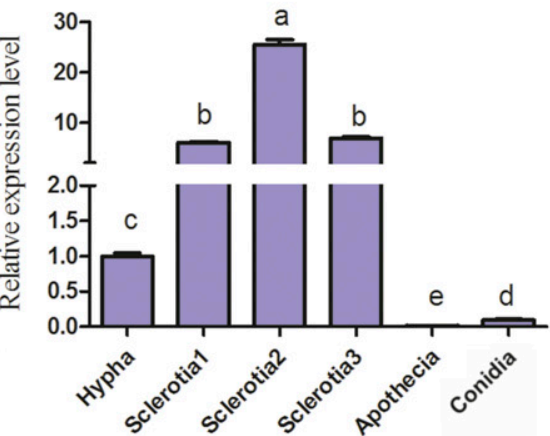

K

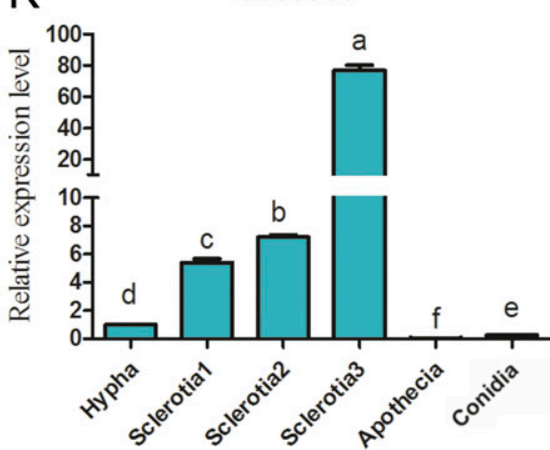

C

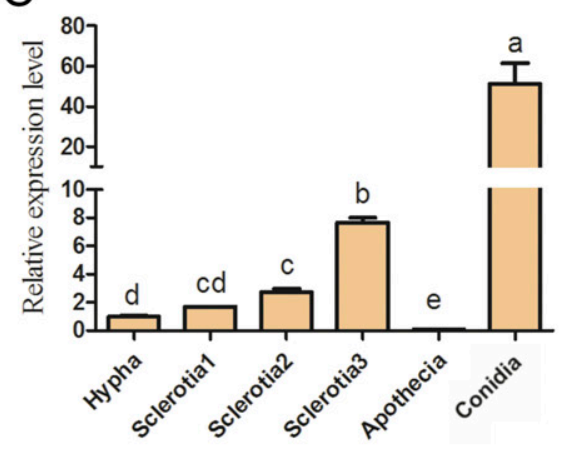

$\mathrm{F}$

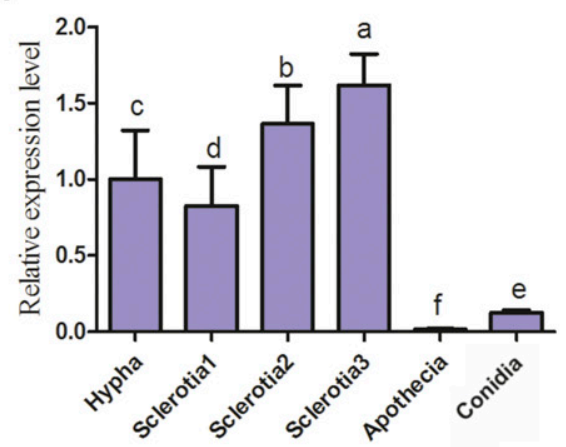

I

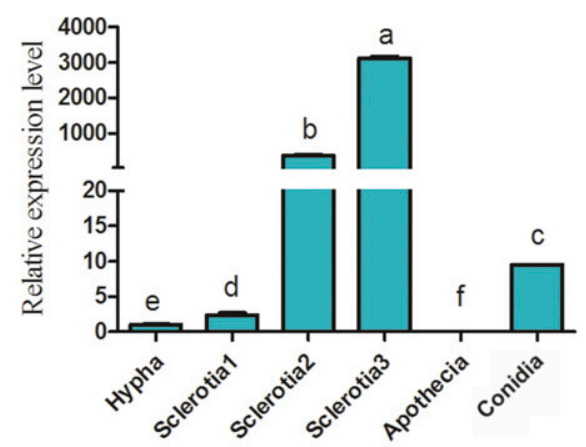

L

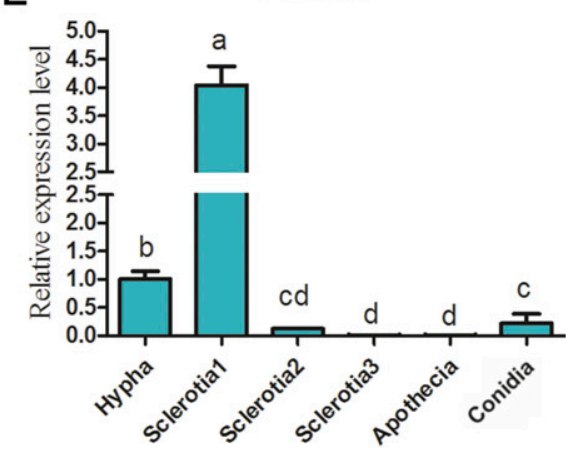

Fig. 4. Detection of the relative expression of predicted growth-related genes in six tissues (hyphae, sclerotia1 = initial sclerotia, sclerotia2 = developmental sclerotia, sclerotia3 = mature sclerotia, apothecia, and conidia) of Ciboria shiraiana by quantitative real-time reverse-transcription PCR. A, Relative expression of sclerotia development-related gene is shown in gray. $\mathbf{B}$ to $\mathbf{E}$, Relative expressions of apothecia formation-related genes are shown in orange. $\mathbf{F}$ to $\mathbf{H}$, Relative expression of infection of mulberry fruit-related genes is indicated in blue. $\mathbf{I}$ to $\mathbf{L}$, Relative expressions of sclerotia formation-related genes are denoted in green. Data presented represent mean \pm standard deviation of triplicate measurements. 
expression of $C s 09614, C s 13590$, and Cs11302 during the six development stages of $C$. shiraiana implied that the infectionassociated genes are also related to development (Fig. 4F to $\mathrm{H}$ ). The expression of these three genes was detected at different periods of infection on detached tomato leaves, and the qRTPCR results revealed that the transcription of $\mathrm{Cs} 09614$ and Cs 13590 increased in the late stage of infection (72 to $96 \mathrm{~h}$ ), while that of $C s 11302, C s 04366$, and Cs 12286 increased during all the stages of infection, when compared with the noninfected group (Fig. 5).

In many fungi, sclerotia formation is considered to play an important role in protection from adverse conditions. Genes associated with sclerotia formation include sclerotium-specific protein Sspl (Li and Rollins 2010), microbial opsin homolog Sopl (Lyu et al. 2016a), oxaloacetate acetylhydrolase gene $\mathrm{Ss}$ oahl (Liang et al. 2015), and so on. These genes were also detected in the $C$. shiraiana genome (Supplementary Table S7), and the qRT-PCR results revealed that the expression of Cs08397, Cs12804, Cs00985, and Cs12286 increased during sclerotia development stages, implying that these genes are associated with sclerotia formation (Fig. 4I to L).

Thus, genes involved in sclerotia dormancy, apothecia formation, infection of mulberry fruit, and sclerotia formation play vital roles in $C$. shiraiana infection and lifecycle. Because ascospores from the apothecia of $C$. shiraiana might play a key role in infection of mulberry fruits owing to its significantly large pathogen base, our future research will focus on development of strategies to block apothecia formation.

\section{Expression analysis of plant cell-wall-degradation genes during infection.}

Plant cell wall carbohydrates are mainly composed of cellulose and pectin. Previous studies have reported that cellulase and pectinase expressed in vitro could enzymatically hydrolyze the cell wall of mulberry plant (Lü et al. 2015a), indicating that these enzymes play important roles in the infection process. The process of infection is very fast; therefore, in the present study, the infected leaves were collected at $0,1,3,6,12$, and $24 \mathrm{~h}$ postinoculation to analyze the expression patterns of cellulase- and pectinase-coding genes. The RT-PCR results showed that all 14 cellulase genes were expressed during infection, among which 8 genes showed an increased expression pattern in the initial stage of infection $(1,3$, or $6 \mathrm{~h}$ after inoculation) (Fig. 6). The expression levels of all of the cellulase genes, except Cs00913 and Cs01714, were increased at $24 \mathrm{~h}$ postinoculation, when compared with those after $12 \mathrm{~h}$ of inoculation. It must be noted that the expression of $\mathrm{Cs} 07879$, Cs 12956 , and Cs07604 gradually increased along with infection duration and peaked at $24 \mathrm{~h}$ (Fig. 6).

Previous studies have shown that the GH28 family plays an important role in pectin degradation in pathogens (Zhao et al. 2013). In the present study, all 16 genes within the pectinase gene family were expressed during the process of infection, among which the expression pattern of 12 genes showed a peak at $6 \mathrm{~h}$, suggesting that these genes may play a significant role during the initiation of infection (Fig. 7). In addition, the expression of $\mathrm{Cs} 05107$ gradually increased along with infection duration, indicating that this gene may be crucial for the pathogenicity of $C$. shiraiana.

\section{DISCUSSION}

Mulberry fruit scleroteniosis is one of the most common and destructive diseases of mulberry in China and around the world; however, studies of its pathogenic mechanism are still limited. It has been reported that repeat sequences can result in significant differences in the entire architecture of the genome and cause different genetic variations so that organisms can better adapt to environmental changes and occupy novel niches (Faino et al. 2016; Lisch 2013). Most of the pathogenic ascomycetes fungi have a slightly higher percentage of repeat elements than nonpathogenic fungi (Hittalmani et al. 2016), such as $S$. sclerotiorum, which has a genome size of $38.3 \mathrm{Mb}$ and TE content of 7\% (Amselem et al. 2011). Although repeat sequences may play a beneficial role in improving genetic diversity, some of them are also detrimental, particularly with respect to genome stability (Galagan et al. 2005). The low percentage of repeats can also be attributed to the function of repeat-induced point (RIP) mutations in the genome (Galagan and Selker 2004). The genomes of other Ascomycetes fungi
Cs09614
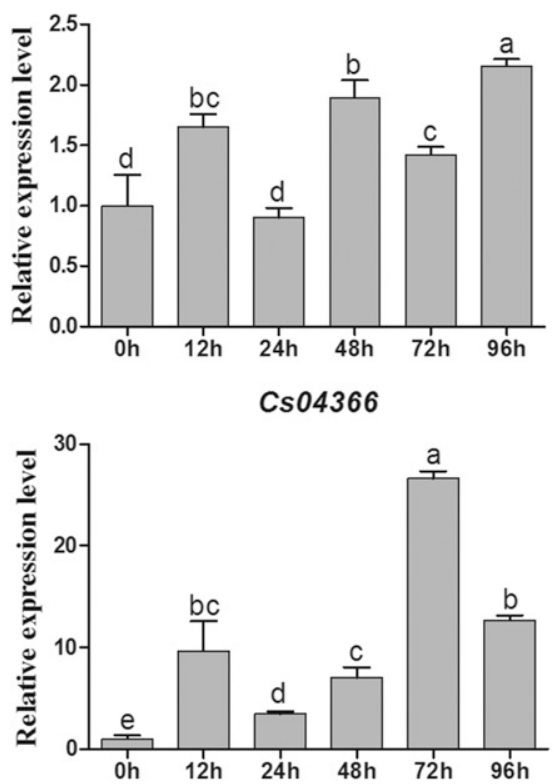

Cs13590
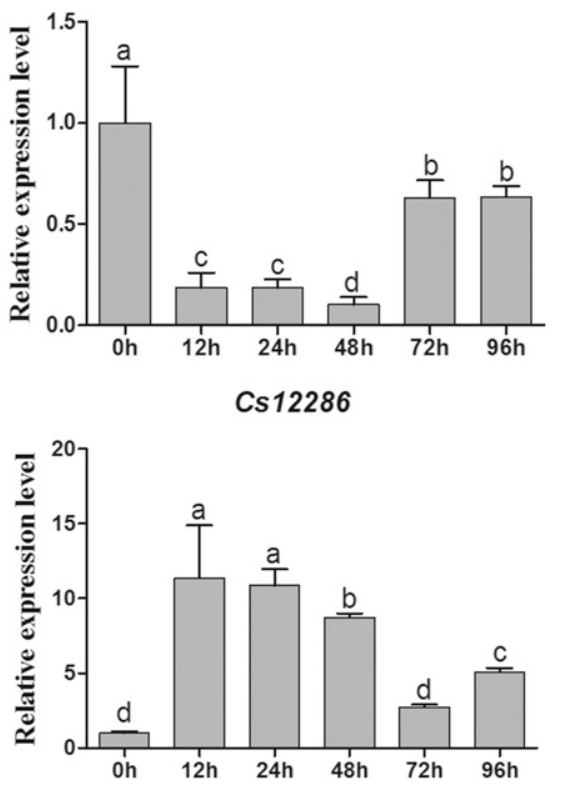

Cs11302

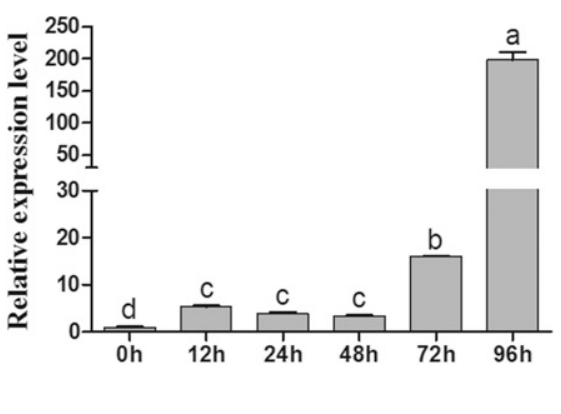

Fig. 5. Expression level of infection-related genes at different periods on detached tomato leaves. Data presented represent mean \pm standard deviation of triplicate measurements. 
such as $S$. sclerotiorum and $B$. cinerea have been observed to exhibit higher repeat elements content along with the RIP mechanism (Amselem et al. 2011). Thus, these fungal species may have a close relationship with $C$. shiraiana, probably sharing similar phenomenon such as RIP in their genomes (Galagan and Selker 2004).

CAZymes play an important role in the degradation of cell wall components during the infection process (Xu et al. 2016). Peltaster fructicola, a pathogen that cannot penetrate host cell walls, contains only 38 putative plant cell wall-degrading enzymes (PCWDEs); this number is slightly higher than the number of PCWDEs in saprophytic Saccharomyces cerevisiae and symbiotic Rhizophagus irregularis but is significantly lower than the number of PCWDEs in most of the plantpathogenic fungi, indicating that the number of CAZymes has a positive effect on pathogenesis (Xu et al. 2016). In most of the obligate biotrophs such as Oidium heveae, Ustilago maydis, and Sporisorium scitamineum, the number of CAZymes has been observed to be significantly lower than that in hemibiotrophic and necrotrophic phytopathogens; as a result, these obligate biotrophs cause minimum damage to the host cell and do not trigger plant defense responses (Kämper et al. 2006; Liang et al. 2018; Que et al. 2014). The decrease in the number of CAZymes in obligate biotrophs suggests the reduction in the requirement of these fungi to attack their hosts, which seems to perfectly match their biotrophic lifestyle (Que et al. 2014). In the present study, $C$. shiraiana was found to exhibit the maximum number of CAZymes among the three necrotrophic fungi, which is in line with its necrotrophic lifestyle and ability to cause infection similar to Sclerotinia sclerotiorum and Botrytis cinerea (Table 2).

Tomato is one of the most important vegetables around the world, with important economic value. It is widely used as a model plant in research on fruit development and biotic stress owing to its short growth period. A cross-infection study on $C$. shiraiana and S. sclerotiorum has revealed that the ascospores of $C$. shiraiana could infect oilseed rape, while those of $S$. sclerotiorum could similarly infect sorosis (Lü et al. 2015 b). In the present study, preliminary experiments showed that $C$. shiraiana could infect tomato leaves in the short term and can serve as a model for performing infection experiments. The RT-PCR results indicated that all 14 cellulase genes were expressed during infection, among which 8 genes showed increased expression patterns in the initial stage of infection (Fig. 6). Similarly, all 15 genes within the pectinase gene family were expressed in the process of infection, among which the expression pattern of 11 genes presented a peak at $6 \mathrm{~h}$ postinfection, implying that this time point may be an important stage during infection (Fig. 7). Because only a few CWDEs have been reported thus far to have an important role in fungal pathogenicity (Baroncelli et al. 2016), the results of the present study will lay the foundation for a better understanding of the role of CWDEs in fungal pathogenicity.
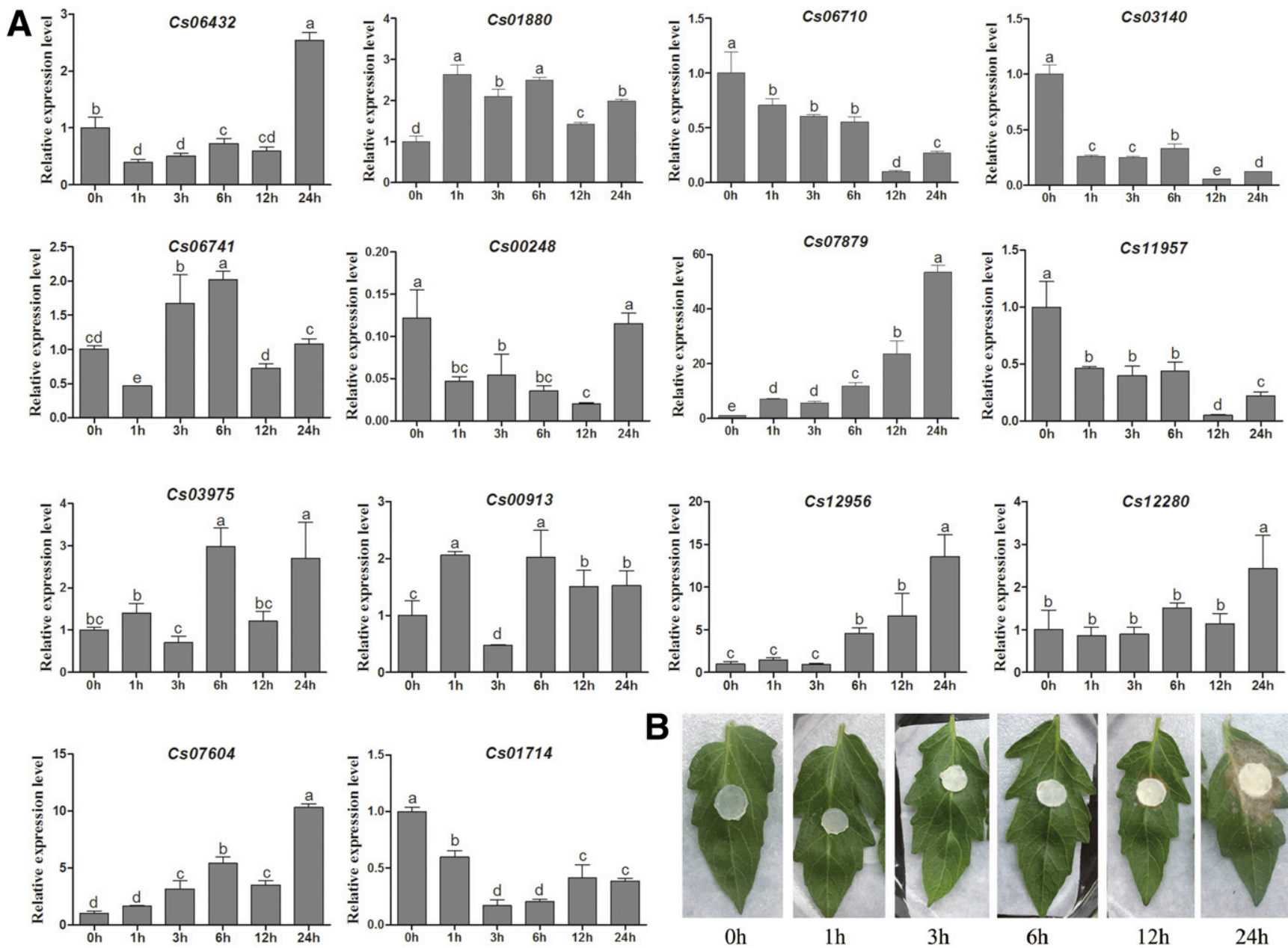

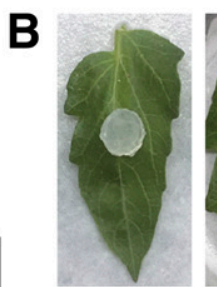

$\mathrm{Oh}$

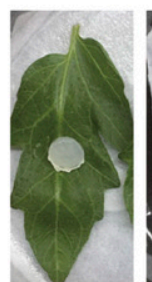

$1 \mathrm{~h}$

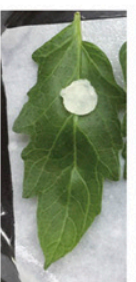

$3 \mathrm{~h}$

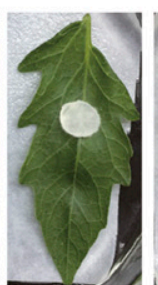

$6 \mathrm{~h}$

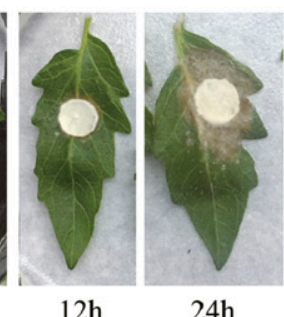

Fig. 6. A, Expression pattern of predicted genes encoding cellulose-degrading enzymes in Ciboria shiraiana at six stages (0, 1,3 , 6, 12 , and 24 h after inoculation) of the infection process. B, Diseased tomato leaves at the indicated times after inoculation. 
To successfully infect hosts, pathogenic fungi must inhibit or avoid activation of plant defense responses. Accordingly, pathogens secrete effectors that play important roles within or outside of the plant cells, interacting with various host targets to suppress PTI and promote colonization (Guyon et al. 2014). The secreted effector proteins have been found to participate in the interactions between biotrophic or hemibiotrophic pathogens and their hosts such as biotrophic powdery mildews (Spanu et al. 2010), smuts, and rusts (Ravensdale et al. 2011; Schirawski et al. 2010), as well as hemibiotroph M. oryzae (Khang et al. 2010), in a gene-for-gene manner (De-Wit et al. 2009). In addition, secreted enzymes can act as virulence factors to improve the catalytic activity of pathogens (Lanver et al. 2017; Noda et al. 2010). The number of effectors may vary among different pathogens and are related to the pathogen's lifestyle (Lowe and Howlett 2012); in particular, the interactions of necrotrophs with their hosts are considerably more complex than previously considered. However, the association between the number of effectors in necrotrophs and broad host range remains unclear. To date, many interactions between host-specific necrotrophic fungal pathogen effectors and their hosts have been reported, including Tsnl in wheat as well as SnToxl-Snn1 in the Stagonospora nodorum-wheat pathosystem, which presented an inverse gene-for-gene activity (Faris et al. 2010; Liu et al. 2004; Lyu et al. 2016b). The number of predicted secreted effector proteins in $C$. shiraiana was observed to be much lower than that in $B$. cinerea (521 proteins) and Sclerotinia sclerotiorum (363 proteins) (Amselem et al. 2011). Comparative secretome analysis of $S$. sclerotiorum has revealed that a diverse effector repertoire confers the ability to infect a broad range of host species (Guyon et al. 2014). In the present study, a small number of predicted secreted effector proteins indicated a narrow host range of $C$. shiraiana, despite comparable numbers of CAZymes among the three necrotrophic fungi.

In fungi, P450 enzymes are known to possess diverse functions ranging from the synthesis of cell wall components to biodegradation of environmental chemicals and drug metabolism (Bhattacharya and Yadav 2018). Plants have the highest number of $\mathrm{P} 450$ genes in different taxa, followed by fungi (Doddapaneni et al. 2005). In the present study, the number of P450 genes was found to be conserved among the three fungal species of Sclerotiniaceae, which present a necrotrophic lifestyle, but was higher than that in the rest of the fungi examined. It is known that plant-pathogenic fungi utilize a variety of strategies to acquire carbon and nitrogen sources from their host plant and counteract the plant defense response. Therefore, we speculated that a high number of $\mathrm{P} 450$ s could contribute to the biodegradation of environmental nutrition to adapt to the necrotrophic lifestyle. Moreover, we found that CYP503A1, a gene family involved in the biosynthesis of gibberellins in the rice pathogen Fusarium fujikuroi (Črešnar and Petrič 2011; Rojas et al. 2001; Troncoso et al. 2008), has expanded (data not shown). Although the production of gibberellins is not essential for the growth and development of fungi, they may help the fungi to survive in harsh environments. In addition, some studies have shown that gibberellins are related to pathogenicity (Salazar-Cerezo et al. 2018). Thus, the expanded gene family CYP503A1 may be involved in the biosynthesis of gibberellins or any other SMs in C. shiraiana.
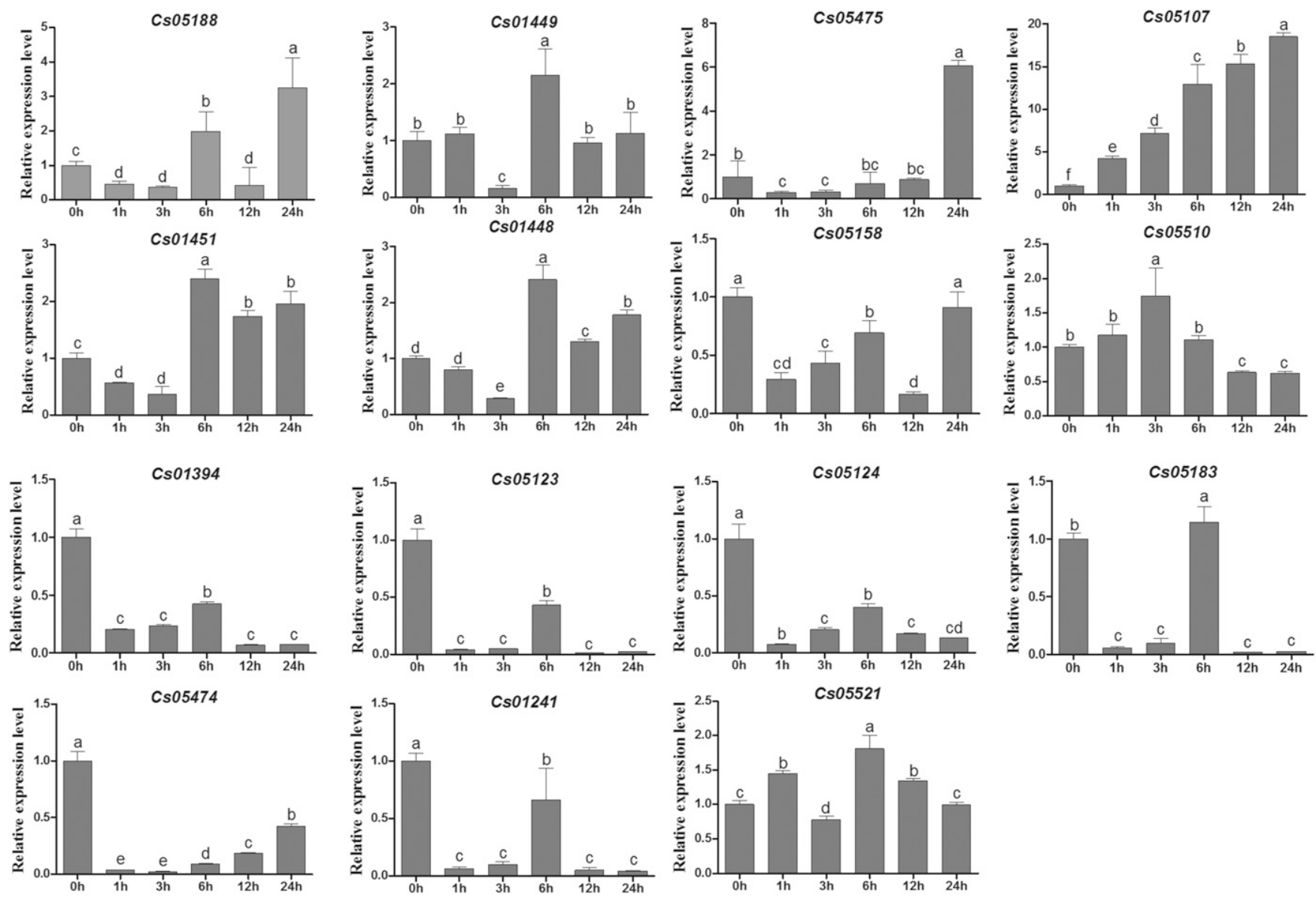

Fig. 7. Expression pattern of predicted genes encoding pectin-degrading enzymes in Ciboria shiraiana at six stages (0, 1, 3, 6, 12, and 24 h after inoculation) of the infection process. 


\section{Conclusion.}

The $C$. shiraiana genome sequencing and comparative analysis with a collection of Ascomycetes genome sequences shed light on the pathogenic mechanisms of this fungus, including secreted effector proteins, CAZymes, secondary metabolism, and P450. In addition, analysis of the key growth-related genes in the $C$. shiraiana life cycle provided molecular targets for the development of antifungal drugs. Following analysis of the $C$. shiraiana genome, efforts are underway to validate the function of all of the potential pathogenicity determinants, especially virulence- and growth-associated genes. The genome sequencing of $C$. shiraiana is the first step in understanding the pathogenic mechanisms of hypertrophy sorosis scleroteniosis at a genomic level. These efforts and ongoing functional identification will expand our knowledge of the interaction between mulberry and $C$. shiraiana, which may help to develop better disease control measures.

\section{MATERIALS AND METHODS}

\section{DNA preparation.}

The sequenced strain C. shiraiana CCTCC AF 2014019 WCCQ01, conserved in our laboratory, was originally isolated and purified from diseased mulberry fruit and deposited in the China Center for Type Culture Collection (Lü et al. 2013). The isolate was grown on potato dextrose agar at $25 \mathrm{C}$ for 3 to 5 days and three mycelia plugs $(5 \mathrm{~mm}$ in diameter) were then transferred to potato dextrose broth and incubated at $25 \mathrm{C}$ and $220 \mathrm{rpm}$ for 3 days. The fungal hyphae were collected from the liquid medium and genomic DNA was extracted by the sodium dodecyl sulfate (SDS) method. Briefly, $0.2 \mathrm{~g}$ of fresh hyphae was quickly homogenized in liquid nitrogen and mixed with $600 \mu \mathrm{l}$ of solution A (200 mM Tris- $\mathrm{HCl}$ [pH 8.0], $250 \mathrm{mM} \mathrm{NaCl}, 25 \mathrm{mM}$ EDTA, $0.5 \%$ SDS, $1 \% \beta$-mercaptoethanol, and $8 \mu \mathrm{l}$ of RNase) using a vortex mixer for $1 \mathrm{~min}$ and allowed to stand for $10 \mathrm{~min}$. After that, $260 \mu \mathrm{l}$ of $5 \mathrm{M}$ potassium acetate was added to the extracted mixture and centrifuged at 12,000 rpm for $5 \mathrm{~min}$. The supernatant was transferred into a new centrifuge tube and the same volume $(500 \mu \mathrm{l})$ of isopropyl alcohol was added and centrifuged at 12,000 rpm for 5 min. Finally, the deposit was collected and washed thrice with $400 \mu \mathrm{l}$ of $75 \%$ ethanol and the genomic DNA was resuspended in $60 \mu \mathrm{l}$ of DNase-free water containing RNase A.

\section{Genome sequencing and assembly.}

The sequence of $C$. shiraiana genome was examined and assembled by Genedenovo Biotechnology Co., Ltd., Guangzhou, China. We first used high-throughput Illumina sequencing technology to perform paired-end sequencing of the $C$. shiraiana genome and then sequenced the genome with PacBio RSII. The genomic data from the two kinds of sequencing technology were assembled together using HGAP software (Chin et al. 2013). Polymerase reads were filtered for quality (eliminate length $<100$, quality $<0.80$ ), adapter, and other contamination, and the resulting 634,414 subreads were assembled using the HGAP assembler.

\section{Karyotype analysis of $C$. shiraiana.}

Three mycelia plugs ( $5 \mathrm{~mm}$ in diameter) were transferred to $25 \mathrm{ml}$ of potato dextrose broth and incubated at $25^{\circ} \mathrm{C}$ and $220 \mathrm{rpm}$ for 3 days. Then, $0.2 \mathrm{~g}$ of fresh fungal mycelia collected from potato dextrose broth was centrifuged at $4 \mathrm{C}$ and 4,000 rpm for $3 \mathrm{~min}$, then fixed in $1 \mathrm{ml}$ of $3: 1$ methanol and glacial acetic acid for $24 \mathrm{~h}$ at $4^{\circ} \mathrm{C}$. The fixed mycelia were incubated with $500 \mu \mathrm{l}$ of $1 \times$ phosphate-buffered saline (PBS) solution for $30 \mathrm{~min}$ and digested with $0.01 \%$ (wt/vol) lyticase and $0.01 \%(\mathrm{wt} / \mathrm{vol})$ snailase for $2 \mathrm{~h}$ at $30^{\circ} \mathrm{C}$. The digested mycelia were immersed in $500 \mu \mathrm{l}$ of double-distilled $\mathrm{H}_{2} \mathrm{O}$ for
$30 \mathrm{~min}$ and smashed using a homogenizer after the addition of $200 \mu \mathrm{l}$ of $1 \times \mathrm{PBS}$ solution and centrifugation at $4^{\circ} \mathrm{C}$ and 4,000 rpm for $3 \mathrm{~min}$. Then, two drops of the cell suspension were placed on a glass slide for staining with $10 \%$ Giemsa in phosphate buffer ( $\mathrm{pH} \mathrm{6.8)}$ at room temperature for $6 \mathrm{~h}$, and analyzed under a compound microscope using bright field at $\times 1,000$ magnification (Leica DM 2500, Germany).

\section{Synteny analysis with $S$. sclerotiorum.}

Synteny analysis was performed at nucleotide and amino acid levels using MUMmer software and BLAST-2.2.26 (1 $\mathrm{e}^{-5}$, soft masked) (Marçais et al. 2018), respectively. The minimum alignment similarity was set at $85 \%, 1: 1$ matches were selected in this alignment, and only best matches with local mapping of the reference to query were selected using $\Delta$-filter. The best protein match was found between the two species by BLASTbased homology alignment, and the synteny region between the two genomes was determined based on their position on the genome. The picture was generated using mummerplot based on the best_delta results.

\section{Genome annotation.}

The ab initio gene predictor tool AUGUSTUS (Stanke et al. 2004) was used to predict gene models in the genome, trained with $S$. sclerotiorum. The AUGUSTUS gene prediction program was employed with options set for (i) S. sclerotiorum, (ii) coding sequence, and (iii) GFF (Stanke and Waack 2003). Prediction of rRNA was performed using rRNAmmer software (Lagesen et al. 2007), and prediction of the tRNA region and secondary structure of tRNA was accomplished by tRNAscan software (Lowe and Eddy 1997). TEs were identified by RepeatMasker, a software for genomic repeat identification that can be used for almost all species.

\section{Analysis of gene family.}

The analysis of gene family was based on the Treefam model, which defines a gene family as a group of genes that had descended from a single gene in the last common ancestor of the considered species ( $\mathrm{Li}$ et al. 2006). Protein sequences from S. sclerotiorum, S. borealis, Blumeria graminis, Pyronema omphalodes, and Saccharomyces cerevisiae were downloaded from NCBI. The longest encoding sequence was selected to represent each gene, and sequences of less than 30 amino acids were removed. The genes that belong to one family were identified based on one of the following criteria: (i) they are phylogenetically separated from other genes or (ii) they lack homologs outside the fungal kingdom. Phylogenetic trees were constructed for each specific gene family and parameters such as $\mathrm{Ka}$ and $\mathrm{Ks}$ nucleotide substitution rates were also analyzed. $\mathrm{The} \mathrm{Ka} / \mathrm{Ks}$ values were used to analysis diversifying selection. A high pairwise $\mathrm{Ka} / \mathrm{Ks}$ value under positive selection indicates that the protein had evolved rapidly in the species. The sequences from each family were aligned using MAFFT and RevTrans based on the protein sequences and codon alignments after translation. KaKs_Calculator 2.0 was used to obtain pairwise $\mathrm{Ka} / \mathrm{Ks}$ values with significance level (Wang et al. 2010).

\section{Analysis of secreted effector proteins.}

Secreted effector proteins were analyzed by using online tools. SignalP was used to screen the signal peptide site, TMHMM version 2.0 was employed to predict the transmembrane helix structure, TargetP 1.1 was utilized to predict the signal peptide related to organelles that were removed, and PredGPI was used to predict glycosyl phosphatidyl inositolanchor signals, which were also filtered out, and the remaining 120 sequences were considered as the potential secreted effector proteins (Amselem et al. 2011; Pedersen et al. 2012). 


\section{CAZymes and auxiliary proteins annotation.}

Two different online tools were used to analyze CAZymes and auxiliary proteins; namely, CAT and dbCAN (E-value $<1.0 \times 10^{-5}$ ), respectively; and all of the results were combined and finally collected. The integration results were mainly based on dbCAN, supplemented with CAT (pfam rules method). One gene could retain only one optimal CAZy family result. The filtering criteria were identity $\geq 40$ and query $\geq 70 \%$, and were classified into reaction catalyzed such as GHs, CBMs, CEs, GTs, and PLs, as described in CAZY database.

\section{CYP450 annotation.}

The CYP450 analysis was based on an online database. The screening criteria (identity $\geq 40$, query $\geq 70 \%$ ) were subjected to multiple filtering, and each gene retained only the best match.

\section{TFs.}

The analysis of TFs was based on the annotation results of the $\mathrm{nr}$ database, and the comment lines related to TFs were filtered from the annotation results and subjected to multiple filtering (E-value $<1 \mathrm{e}^{-5}$, identity $>70$, query coverage $>40 \%$ ). The final 291 genes were noted to be putative TFs.

\section{Secondary metabolism.}

The antiSMASH database was used to search the SM gene clusters. Briefly, the potential biosynthetic gene clusters were identified by profile hidden Markov models (pHMMs), and 24 secondary metabolite classes of pHMMs describing the key biosynthetic enzymes were detected by HMMer3 software. Based on the detected secondary metabolite gene cluster, further detailed analyses were performed using a pHMM-based approach. All of the above-mentioned programs and software used have been integrated in antiSMASH. Finally, the putative product biosynthesis gene clusters between the genomes were obtained.

\section{qRT-PCR expression analysis.}

Primers (Supplementary Table S1) used for qRT-PCR were designed based on the genomic sequences of $C$. shiraiana. To analyze gene expression, the total RNA was extracted using the RNA Extraction Kit TransZol Plant (TransGenBiotech, Beijing, China) according to the manufacturer's protocol. Firststrand cDNA was synthesized using the PrimeScript RT Reagent Kit (TaKaRa, Japan). The $\beta$-tubulin gene (Ciboria_shiraiana05660) was used as an internal reference, and the $2^{-\Delta \Delta \mathrm{Ct}}$ method was employed to calculate the relative expression levels (Livak and Schmittgen 2001).

\section{Plant growth conditions and $C$. shiraiana infection.}

Tomato plants (Solanum lycopersicum) were cultured in incubator at 25 and $18^{\circ} \mathrm{C}$ (day and night, respectively) with a daily cycle of $16 \mathrm{~h}$ of light and $8 \mathrm{~h}$ of darkness. The leaves of 3month-old tomato seedlings were used for infection experiments. Before an infection test, all of the leaves were surface sterilized with $75 \%$ ethanol for $1 \mathrm{~min}$, then put in a petri dish covered with a damp filter paper. Fresh mycelium pieces cultured for 3 days in potato dextrose agar were used for infection. The leaves and agar mycelium were collected at $0,1,3,6,12$, $24,36,48$, and $72 \mathrm{~h}$ postincubation for RNA extraction. Each treatment contained three independent biological replicates and each replicate comprised three leaves. The primers used in the experiments are listed in Supplementary Tables S8 and S9.

\section{AUTHOR-RECOMMENDED INTERNET RESOURCES}

antiSMASH database: https://fungismash.secondarymetabolites.org/\#!/start CAT: https://github.com/ComparativeGenomicsToolkit/ComparativeAnnotation-Toolkit
CAZY database:

http://www.cazy.org/Welcome-to-the-Carbohydrate-Active.html) CYP450 online database: https://drnelson.uthsc.edu/cytochromeP450.html dbCAN: http://csbl.bmb.uga.edu/new/?page_id=13073

NCBI: https://www.ncbi.nlm.nih.gov

PredGPI http://gpcr.biocomp.unibo.it/predgpi

RepeatMasker: http://www.repeatmasker.org

SignalP: http://www.cbs.dtu.dk/services/SignalP)

TargetP: http://www.cbs.dtu.dk/services/TargetP

TMHMM: http://www.cbs.dtu.dk/services/TMHMM

\section{LITERATURE CITED}

Amselem, J., Cuomo, C. A., van Kan, J. A. L., Viaud, M., Benito, E. P., Couloux, A., Coutinho, P. M., de Vries, R. P., Dyer, P. S., Fillinger, S., Fournier, E., Gout, L., Hahn, M., Kohn, L., Lapalu, N., Plummer, K. M., Pradier, J. M., Quévillon, E., Sharon, A., Simon, A., ten Have, A., Tudzynski, B., Tudzynski, P., Wincker, P., Andrew, M., Anthouard, V., Beever, R. E., Beffa, R., Benoit, I., Bouzid, O., Brault, B., Chen, Z., Choquer, M., Collémare, J., Cotton, P., Danchin, E. G., Da Silva, C., Gautier, A., Giraud, C., Giraud, T., Gonzalez, C., Grossetete, S., Güldener, U., Henrissat, B., Howlett, B. J., Kodira, C., Kretschmer, M., Lappartient, A., Leroch, M., Levis, C., Mauceli, E., Neuvéglise, C., Oeser, B., Pearson, M., Poulain, J., Poussereau, N., Quesneville, H., Rascle, C., Schumacher, J., Ségurens, B., Sexton, A., Silva, E., Sirven, C., Soanes, D. M., Talbot, N. J., Templeton, M., Yandava, C., Yarden, O., Zeng, Q., Rollins, J. A., Lebrun, M. H., and Dickman, M. 2011. Genomic analysis of the necrotrophic fungal pathogens Sclerotinia sclerotiorum and Botrytis cinerea. PLoS Genet. 7:e1002230.

Baroncelli, R., Amby, D. B., Zapparata, A., Sarrocco, S., Vannacci, G., Le Floch, G., Harrison, R. J., Holub, E., Sukno, S. A., Sreenivasaprasad, S., and Thon, M. R. 2016. Gene family expansions and contractions are associated with host range in plant pathogens of the genus Colletotrichum. BMC Genomics 17:555.

Bhattacharya, S. S., and Yadav, J. S. 2018. Microbial P450 enzymes in bioremediation and drug discovery: Emerging potentials and challenges. Curr. Protein Pept. Sci. 19:75-86.

Blanc, C., Coluccia, F., L'Haridon, F., Torres, M., Ortiz-Berrocal, M., Stahl, E., Reymond, P., Schreiber, L., Nawrath, C., Métraux, J. P., and Serrano, M. 2018. The cuticle mutant eca2 modifies plant defense responses to biotrophic and necrotrophic pathogens and herbivory insects. Mol. PlantMicrobe Interact. 31:344-355.

Boller, T., and Felix, G. 2009. A renaissance of elicitors: Perception of microbe-associated molecular patterns and danger signals by patternrecognition receptors. Annu. Rev. Plant Biol. 60:379-406.

Bolton, M. D., Thomma, B. P., and Nelson, B. D. 2006. Sclerotinia sclerotiorum (Lib.) de Bary: Biology and molecular traits of a cosmopolitan pathogen. Mol. Plant Pathol. 7:1-16.

Bos, J. I., Kanneganti, T. D., Young, C., Cakir, C., Huitema, E., Win, J., Armstrong, M. R., Birch, P. R., and Kamoun, S. 2006. The C-terminal half of Phytophthora infestans RXLR effector AVR3a is sufficient to trigger R3a-mediated hypersensitivity and suppress INF1-induced cell death in Nicotiana benthamiana. Plant J. 48:165-176.

Chin, C. S., Alexander, D. H., Marks, P., Klammer, A. A., Drake, J., Heiner, C., Clum, A., Copeland, A., Huddleston, J., Eichler, E. E., Turner, S. W., and Korlach, J. 2013. Nonhybrid, finished microbial genome assemblies from long-read SMRT sequencing data. Nat. Methods 10:563-569.

Črešnar, B., and Petrič, Š. 2011. Cytochrome P450 enzymes in the fungal kingdom. Biochim. Biophys. Acta 1814:29-35.

De Wit, P. J., Mehrabi, R., Van den Burg, H. A., and Stergiopoulos, I. 2009. Fungal effector proteins: Past, present and future. Mol. Plant Pathol. 10: 735-747.

Doddapaneni, H., Chakraborty, R., and Yadav, J. S. 2005. Genome-wide structural and evolutionary analysis of the P450 monooxygenase genes (P450ome) in the white rot fungus Phanerochaete chrysosporium: Evidence for gene duplications and extensive gene clustering. BMC Genomics 6: 92.

Dodds, P. N., and Rathjen, J. P. 2010. Plant immunity: Towards an integrated view of plant-pathogen interactions. Nat. Rev. Genet. 11: 539-548.

Dou, D., Kale, S. D., Wang, X., Chen, Y., Wang, Q., Wang, X., Jiang, R. H., Arredondo, F. D., Anderson, R. G., Thakur, P. B., McDowell, J. M., Wang, Y., and Tyler, B. M. 2008. Conserved C-terminal motifs required for avirulence and suppression of cell death by Phytophthora sojae effector Avr1b. Plant Cell 20:1118-1133.

Faino, L., Seidl, M. F., Shi-Kunne, X., Pauper, M., van den Berg, G. C., Wittenberg, A. H., and Thomma, B. P. 2016. Transposons passively and 
actively contribute to evolution of the two-speed genome of a fungal pathogen. Genome Res. 26:1091-1100.

Faris, J. D., Zhang, Z., Lu, H., Lu, S., Reddy, L., Cloutier, S., Fellers, J. P., Meinhardt, S. W., Rasmussen, J. B., Xu, S. S., Oliver, R. P., Simons, K. J., and Friesen, T. L. 2010. A unique wheat disease resistance-like gene governs effector-triggered susceptibility to necrotrophic pathogens. Proc. Natl. Acad. Sci. U.S.A. 107:13544-13549.

Galagan, J. E., Henn, M. R., Ma, L. J., Cuomo, C. A., and Birren, B. 2005 Genomics of the fungal kingdom: Insights into eukaryotic biology. Genome Res. 15:1620-1631.

Galagan, J. E., and Selker, E. U. 2004. RIP: The evolutionary cost of genome defense. Trends Genet. 20:417-423.

Guo, M., Chen, Y., Du, Y., Dong, Y., Guo, W., Zhai, S., Zhang, H., Dong, S., Zhang, Z., Wang, Y., Wang, P., and Zheng, X. 2011. The bZIP transcription factor MoAP1 mediates the oxidative stress response and is critical for pathogenicity of the rice blast fungus Magnaporthe oryzae. PLoS Pathog. 7:e1001302.

Guo, M., Guo, W., Chen, Y., Dong, S., Zhang, X., Zhang, H., Song, W., Wang, W., Wang, Q., Lv, R., Zhang, Z., Wang, Y., and Zheng, X. 2010. The basic leucine zipper transcription factor Moatf1 mediates oxidative stress responses and is necessary for full virulence of the rice blast fungus Magnaporthe oryzae. Mol. Plant-Microbe Interact. 23: 1053-1068.

Guyon, K., Balagué, C., Roby, D., and Raffaele, S. 2014. Secretome analysis reveals effector candidates associated with broad host range necrotrophy in the fungal plant pathogen Sclerotinia sclerotiorum. BMC Genomics 15:336.

Hittalmani, S., Mahesh, H. B., Mahadevaiah, C., and Prasannakumar, M. K 2016. De novo genome assembly and annotation of rice sheath rot fungus Sarocladium oryzae reveals genes involved in helvolic acid and cerulenin biosynthesis pathways. BMC Genomics 17:271

Hurst, L. D. 2002. The $\mathrm{Ka} / \mathrm{Ks}$ ratio: Diagnosing the form of sequence evolution. Trends Genet. 18:486-487.

Kämper, J., Kahmann, R., Bölker, M., Ma, L. J., Brefort, T., Saville, B. J., Banuett, F., Kronstad, J. W., Gold, S. E., Müller, O., Perlin, M. H., Wösten, H. A. B., de Vries, R., Ruiz-Herrera, J., Reynaga-Peña, C. G., Snetselaar, K., McCann, M., Pérez-Martín, J., Feldbrügge, M., Basse, C. W., Steinberg, G., Ibeas, J. I., Holloman, W., Guzman, P., Farman, M., Stajich, J. E., Sentandreu, R., González-Prieto, J. M., Kennell, J. C., Molina, L., Schirawski, J., Mendoza-Mendoza, A., Greilinger, D., Münch, K., Rössel, N., Scherer, M., Vraneš, M., Ladendorf, O., Vincon, V., Fuchs, U., Sandrock, B., Meng, S., Ho, E. C. H., Cahill, M. J., Boyce, K. J., Klose, J., Klosterman, S. J., Deelstra, H. J., Ortiz-Castellanos, L., Li, W., Sanchez-Alonso, P., Schreier, P. H., Häuser-Hahn, I., Vaupel, M., Koopmann, E., Friedrich, G., Voss, H., Schlüter, T., Margolis, J., Platt, D., Swimmer, C., Gnirke, A., Chen, F., Vysotskaia, V., Mannhaupt, G., Güldener, U., Münsterkötter, M., Haase, D., Oesterheld, M., Mewes, H. W., Mauceli, E. W., DeCaprio, D., Wade, C. M., Butler, J., Young, S., Jaffe, D. B., Calvo, S., Nusbaum, C., Galagan, J., and Birren, B. W. 2006. Insights from the genome of the biotrophic fungal plant pathogen Ustilago maydis. Nature 444:97-101.

Kars, I., Krooshof, G. H., Wagemakers, L., Joosten, R., Benen, J. A., and van Kan, J. A. 2005. Necrotizing activity of five Botrytis cinerea endopolygalacturonases produced in Pichia pastoris. Plant J. 43: 213-225.

Khang, C. H., Berruyer, R., Giraldo, M. C., Kankanala, P., Park, S. Y., Czymmek, K., Kang, S., and Valent, B. 2010. Translocation of Magnaporthe oryzae effectors into rice cells and their subsequent cellto-cell movement. Plant Cell 22:1388-1403.

Kim, H. R., Chae, K. S., Han, K. H., and Han, D. M. 2009. The $n s d C$ gene encoding a putative $\mathrm{C}_{2} \mathrm{H}_{2}$-type transcription factor is a key activator of sexual development in Aspergillus nidulans. Genetics 182:771-783.

Kishi, K. 1998. Plant Disease in Japan. Zenkaku Noson Kyoiku Kyokai Co., Ltd., Tokyo, Japan.

Kohn, L. M., and Nagasawa, E. 1984. The genus Scleromitrula (Sclerotiniaceae), Episclerotium gen. nov. (Leotiacwae) and allied stipitate-capitate species with reduced ectal excipula. Trans. Mycol. Soc. Jpn. 25:23-38

Kuai, Y. Z., and Wu, F. A. 2012. A review on pathogens of mulberry fruit sclerotiniosis and its control technology. Sci. Seric. 38:1099-1104.

Lagesen, K., Hallin, P., Rødland, E. A., Staerfeldt, H. H., Rognes, T., and Ussery, D. W. 2007. RNAmmer: Consistent and rapid annotation of ribosomal RNA genes. Nucleic Acids Res. 35:3100-3108.

Lanver, D., Tollot, M., Schweizer, G., Lo Presti, L., Reissmann, S., Ma L. S., Schuster, M., Tanaka, S., Liang, L., Ludwig, N., and Kahmann, R. 2017. Ustilago maydis effectors and their impact on virulence. Nat. Rev. Microbiol. 15:409-421.
Leroch, M., Mernke, D., Koppenhoefer, D., Schneider, P., Mosbach, A., Doehlemann, G., and Hahn, M. 2011. Living colors in the gray mold pathogen Botrytis cinerea: Codon-optimized genes encoding green fluorescent protein and mCherry, which exhibit bright fluorescence. Appl. Environ. Microbiol. 77:2887-2897.

Li, H., Coghlan, A., Ruan, J., Coin, L. J., Hériché, J. K., Osmotherly, L., Li, R., Liu, T., Zhang, Z., Bolund, L., Wong, G. K., Zheng, W., Dehal, P., Wang, J., and Durbin, R. 2006. TreeFam: A curated database of phylogenetic trees of animal gene families. Nucleic Acids Res. 34: D572-D580.

Li, J., Mu, W., Veluchamy, S., Liu, Y., Zhang, Y., Pan, H., and Rollins, J. A. 2018. The GATA-type IVb zinc-finger transcription factor SsNsd1 regulates asexual-sexual development and appressoria formation in Sclerotinia sclerotiorum. Mol. Plant Pathol. 19:1679-1689.

Li, M., Liang, X., and Rollins, J. A. 2012. Sclerotinia sclerotiorum $\gamma$-glutamyl transpeptidase (Ss-Ggt1) is required for regulating glutathione accumulation and development of sclerotia and compound appressoria. Mol. Plant-Microbe Interact. 25:412-420.

Li, M., and Rollins, J. A. 2010. The development-specific ssp1 and ssp2 genes of Sclerotinia sclerotiorum encode lectins with distinct yet compensatory regulation. Fungal Genet. Biol. 47:531-538.

Li, R., Fan, W., Tian, G., Zhu, H., He, L., Cai, J., Huang, Q., Cai, Q., Li, B. Bai, Y., Zhang, Z., Zhang, Y., Wang, W., Li, J., Wei, F., Li, H., Jian, M. Li, J., Zhang, Z., Nielsen, R., Li, D., Gu, W., Yang, Z., Xuan, Z., Ryder, O. A., Leung, F. C., Zhou, Y., Cao, J., Sun, X., Fu, Y., Fang, X., Guo, X. Wang, B., Hou, R., Shen, F., Mu, B., Ni, P., Lin, R., Qian, W., Wang, G., Yu, C., Nie, W., Wang, J., Wu, Z., Liang, H., Min, J., Wu, Q., Cheng, S., Ruan, J., Wang, M., Shi, Z., Wen, M., Liu, B., Ren, X., Zheng, H., Dong, D., Cook, K., Shan, G., Zhang, H., Kosiol, C., Xie, X., Lu, Z., Zheng, H., Li, Y., Steiner, C. C., Lam, T. T., Lin, S., Zhang, Q., Li, G., Tian, J., Gong, T., Liu, H., Zhang, D., Fang, L., Ye, C., Zhang, J., Hu, W., Xu, A. Ren, Y., Zhang, G., Bruford, M. W., Li, Q., Ma, L., Guo, Y., An, N., Hu, Y., Zheng, Y., Shi, Y., Li, Z., Liu, Q., Chen, Y., Zhao, J., Qu, N., Zhao, S., Tian, F., Wang, X., Wang, H., Xu, L., Liu, X., Vinar, T., Wang, Y., Lam, T. W., Yiu, S. M., Liu, S., Zhang, H., Li, D., Huang, Y., Wang, X., Yang, G., Jiang, Z., Wang, J., Qin, N., Li, L., Li, J., Bolund, L., Kristiansen, K., Wong, G. K., Olson, M., Zhang, X., Li, S., Yang, H., Wang, J., and Wang, J. 2010. The sequence and de novo assembly of the giant panda genome. Nature 463:311-317.

Liang, P., Liu, S., Xu, F., Jiang, S., Yan, J., He, Q., Liu, W., Lin, C., Zheng, F., Wang, X., and Miao, W. 2018. Powdery mildews are characterized by contracted carbohydrate metabolism and diverse effectors to adapt to obligate biotrophic lifestyle. Front. Microbiol. 9:3160.

Liang, X., Liberti, D., Li, M., Kim, Y. T., Hutchens, A., Wilson, R., and Rollins, J. A. 2015. Oxaloacetate acetylhydrolase gene mutants of Sclerotinia sclerotiorum do not accumulate oxalic acid, but do produce limited lesions on host plants. Mol. Plant Pathol. 16:559-571.

Lisch, D. 2013. How important are transposons for plant evolution? Nat. Rev. Genet. 14:49-61.

Liu, Z. H., Faris, J. D., Meinhardt, S. W., Ali, S., Rasmussen, J. B., and Friesen, T. L. 2004. Genetic and physical mapping of a gene conditioning sensitivity in wheat to a partially purified host-selective toxin produced by Stagonospora nodorum. Phytopathology 94 1056-1060.

Livak, K. J., and Schmittgen, T. D. 2001. Analysis of relative gene expression data using real-time quantitative PCR and the $2^{-\Delta \Delta C T}$ method. Methods 25:402-408.

Lowe, R. G., and Howlett, B. J. 2012. Indifferent, affectionate, or deceitful: Lifestyles and secretomes of fungi. PLoS Pathog. 8:e1002515.

Lowe, T. M., and Eddy, S. R. 1997. tRNAscan-SE: A program for improved detection of transfer RNA genes in genomic sequence. Nucleic Acids Res. 25:955-964

Lü, R., Zhao, A., Li, J., Liu, C., Wang, C., Wang, X., Wang, X., Pei, R., Lu, C., and Yu, M. 2015a. Screening, cloning and expression analysis of a cellulase derived from the causative agent of hypertrophy sorosis scleroteniosis, Ciboria shiraiana. Gene 565:221-227.

Lü, R., Zhao, A., Li, J., Wang, X., Yu, Y., Lu, C., and Yu, M. 2013. Biological study of hypertrophy sorosis scleroteniosis and its molecular characterization based on LSU rRNA. Afr. J. Microbiol. Res. 7: 3405-3411.

Lü, R., Zhu, P., Yu, M., Liu, C., and Zhao, A. 2019. Conidial formation and pathogenicity of Ciboria shiraiana. Acta Microbiol. Sin. 59:2367-2377.

Lü, R.-H., Jin, X.-Y., Zhao, A.-C., Ji, J., Liu, C.-Y., Li, J., Pu, L., Lu, C., and Yu, M. D. 2015b. Cross infection, biological characteristics and genetic relationship between pathogens of hypertrophy sorosis sclerotenisis from mulberry and Sclerotinia stem rot from oilseed rape. Acta Agron. Sin 41:42-48. 
Lyu, X., Shen, C., Fu, Y., Xie, J., Jiang, D., Li, G., and Cheng, J. 2016a. The microbial opsin homolog Sop1 is involved in Sclerotinia sclerotiorum development and environmental stress response. Front. Microbiol. 6: 1504.

Lyu, X., Shen, C., Fu, Y., Xie, J., Jiang, D., Li, G., and Cheng, J. 2016b. A small secreted virulence-related protein is essential for the necrotrophic interactions of Sclerotinia sclerotiorum with its host plants. PLoS Pathog. 12:e1005435.

Marçais, G., Delcher, A. L., Phillippy, A. M., Coston, R., Salzberg, S. L., and Zimin, A. 2018. MUMmer4: A fast and versatile genome alignment system. PLOS Comput. Biol. 14:e1005944.

Navarro, A., and Barton, N. H. 2003. Chromosomal speciation and molecular divergence--accelerated evolution in rearranged chromosomes. Science 300:321-324.

Noda, J., Brito, N., and González, C. 2010. The Botrytis cinerea xylanase Xyn11A contributes to virulence with its necrotizing activity, not with its catalytic activity. BMC Plant Biol. 10:38.

Pedersen, C., Ver Loren van Themaat, E., McGuffin, L. J., Abbott, J. C., Burgis, T. A., Barton, G., Bindschedler, L. V., Lu, X., Maekawa, T., Wessling, R., Cramer, R., Thordal-Christensen, H., Panstruga, R., and Spanu, P. D. 2012. Structure and evolution of barley powdery mildew effector candidates. BMC Genomics 13:694.

Pieterse, C. M., Leon-Reyes, A., Van der Ent, S., and Van Wees, S. C. 2009. Networking by small-molecule hormones in plant immunity. Nat. Chem. Biol. 5:308-316.

Que, Y., Xu, L., Wu, Q., Liu, Y., Ling, H., Liu, Y., Zhang, Y., Guo, J., Su, Y., Chen, J., Wang, S., and Zhang, C. 2014. Genome sequencing of Sporisorium scitamineum provides insights into the pathogenic mechanisms of sugarcane smut. BMC Genomics 15:996.

Ravensdale, M., Nemri, A., Thrall, P. H., Ellis, J. G., and Dodds, P. N. 2011. Co-evolutionary interactions between host resistance and pathogen effector genes in flax rust disease. Mol. Plant Pathol. 12:93-102.

Ridout, C. J., Skamnioti, P., Porritt, O., Sacristan, S., Jones, J. D., and Brown, J. K. 2006. Multiple avirulence paralogues in cereal powdery mildew fungi may contribute to parasite fitness and defeat of plant resistance. Plant Cell 18:2402-2414.

Rojas, M. C., Hedden, P., Gaskin, P., and Tudzynski, B. 2001. The P450-1 gene of Gibberella fujikuroi encodes a multifunctional enzyme in gibberellin biosynthesis. Proc. Natl. Acad. Sci. U.S.A. 98:5838-5843.

Salazar-Cerezo, S., Martínez-Montiel, N., García-Sánchez, J., Pérez-YTerrón, R., and Martínez-Contreras, R. D. 2018. Gibberellin biosynthesis and metabolism: A convergent route for plants, fungi and bacteria. Microbiol. Res. 208:85-98.

Schirawski, J., Mannhaupt, G., Münch, K., Brefort, T., Schipper, K., Doehlemann, G., Di Stasio, M., Rössel, N., Mendoza-Mendoza, A. Pester, D., Müller, O., Winterberg, B., Meyer, E., Ghareeb, H., Wollenberg, T., Münsterkötter, M., Wong, P., Walter, M., Stukenbrock, E., Güldener, U., and Kahmann, R. 2010. Pathogenicity determinants in smut fungi revealed by genome comparison. Science 330:1546-1548.

Schumacher, J., de Larrinoa, I. F., and Tudzynski, B. 2008. Calcineurinresponsive zinc finger transcription factor CRZ1 of Botrytis cinerea is required for growth, development, and full virulence on bean plants. Eukaryot. Cell 7:584-601.

Shao, W., Zhang, Y., Wang, J., Lv, C., and Chen, C. 2016. BcMtg2 is required for multiple stress tolerance, vegetative development and virulence in Botrytis cinerea. Sci. Rep. 6:28673.

Siegler, E. A., and Jenkins, A. E. 1922. A new sclerotinia on mulberry. Science 55:353-354.

Sohn, K. H., Lei, R., Nemri, A., and Jones, J. D. 2007. The downy mildew effector proteins ATR1 and ATR13 promote disease susceptibility in Arabidopsis thaliana. Plant Cell 19:4077-4090.

Spanu, P. D., Abbott, J. C., Amselem, J., Burgis, T. A., Soanes, D. M., Stüber, K., Ver Loren van Themaat, E., Brown, J. K., Butcher, S. A., Gurr, S. J., Lebrun, M. H., Ridout, C. J., Schulze-Lefert, P., Talbot, N. J., Ahmadinejad, N., Ametz, C., Barton, G. R., Benjdia, M., Bidzinski, P., Bindschedler, L. V., Both, M., Brewer, M. T., Cadle-Davidson, L., CadleDavidson, M. M., Collemare, J., Cramer, R., Frenkel, O., Godfrey, D., Harriman, J., Hoede, C., King, B. C., Klages, S., Kleemann, J., Knoll, D., Koti, P. S., Kreplak, J., López-Ruiz, F. J., Lu, X., Maekawa, T., Mahanil,
S., Micali, C., Milgroom, M. G., Montana, G., Noir, S., O’Connell, R. J., Oberhaensli, S., Parlange, F., Pedersen, C., Quesneville, H., Reinhardt, R., Rott, M., Sacristán, S., Schmidt, S. M., Schön, M., Skamnioti, P., Sommer, H., Stephens, A., Takahara, H., Thordal-Christensen, H., Vigouroux, M., Wessling, R., Wicker, T., and Panstruga, R. 2010 Genome expansion and gene loss in powdery mildew fungi reveal tradeoffs in extreme parasitism. Science 330:1543-1546.

Stanke, M., Steinkamp, R., Waack, S., and Morgenstern, B. 2004. AUGUSTUS: A web server for gene finding in eukaryotes. Nucleic Acids Res. 32:W309-W312.

Stanke, M., and Waack, S. 2003. Gene prediction with a hidden Markov model and a new intron submodel. Bioinformatics 19:ii215-ii225.

Thomma, B. P. 2003. Alternaria spp.: From general saprophyte to specific parasite. Mol. Plant Pathol. 4:225-236.

Toth, I. K., Bell, K. S., Holeva, M. C., and Birch, P. R. 2003. Soft rot erwiniae: From genes to genomes. Mol. Plant Pathol. 4:17-30.

Troncoso, C., Cárcamo, J., Hedden, P., Tudzynski, B., and Rojas, M. C. 2008. Influence of electron transport proteins on the reactions catalyzed by Fusarium fujikuroi gibberellin monooxygenases. Phytochemistry 69: 672-683.

van den Brink, H. M., van Gorcom, R. F., van den Hondel, C. A., and Punt, P. J. 1998. Cytochrome P450 enzyme systems in fungi. Fungal Genet. Biol. 23:1-17.

van Kan, J. A. 2006. Licensed to kill: The lifestyle of a necrotrophic plant pathogen. Trends Plant Sci. 11:247-253.

Wang, D., Zhang, Y., Zhang, Z., Zhu, J., and Yu, J. 2010. KaKs_Calculator 2.0: A Toolkit incorporating gamma-series methods and sliding window strategies. Genomics Proteomics Bioinf. 8:77-80.

Wang, G. L. 2003. Preliminary studies on the white fruit disease of fruit mulberry. Acta Phytopathol. Sin. 33:477-478.

Wang, G. L. 2009. Diversity investigation of mulberry sclerotiniose pathogen. J. Fungal Res. 7:189-192.

Wang, L., Liu, Y., Liu, J., Zhang, Y., Zhang, X., and Pan, H. 2016. The Sclerotinia sclerotiorum FoxE2 gene is required for apothecial development. Phytopathology 106:484-490.

Whetzel, H. H., and Wolf, F. A. 1945. A cup fungus, Ciboria carunculoides, pathogenic on mulberry fruits. Mycologia 37:476-491.

Wicker, T., Oberhaensli, S., Parlange, F., Buchmann, J. P., Shatalina, M., Roffler, S., Ben-David, R., Doležel, J., Šimková, H., Schulze-Lefert, P., Spanu, P. D., Bruggmann, R., Amselem, J., Quesneville, H., Ver Loren van Themaat, E., Paape, T., Shimizu, K. K., and Keller, B. 2013. The wheat powdery mildew genome shows the unique evolution of an obligate biotroph. Nat. Genet. 45:1092-1096.

Williamson, B., Tudzynski, B., Tudzynski, P., and van Kan, J. A. 2007. Botrytis cinerea: The cause of grey mould disease. Mol. Plant Pathol. 8: 561-580.

Xu, C., Chen, H., Gleason, M. L., Xu, J. R., Liu, H., Zhang, R., and Sun, G. 2016. Peltaster fructicola genome reveals evolution from an invasive phytopathogen to an ectophytic parasite. Sci. Rep. 6:22926.

Yang, R. H., Li, Y., Wáng, Y., Wan, J. N., Zhou, C. L., Wāng, Y., Gao, Y. N., Mao, W. J., Tang, L. H., Gong, M., Wu, Y. Y., and Bao, D. P. 2016. The genome of Pleurotus eryngii provides insights into the mechanisms of wood decay. J. Biotechnol. 239:65-67.

Young, N., and Ashford, A. 1992. Changes during development in the permeability of sclerotia of Sclerotinia minor to an apoplastic tracer. Protoplasma 167:205-214.

Yu, Y., Xiao, J., Du, J., Yang, Y., Bi, C., and Qing, L. 2016. Disruption of the gene encoding endo- $\beta$-1,4-xylanase affects the growth and virulence of Sclerotinia sclerotiorum. Front. Microbiol. 7:1787.

Zhang, Z., Li, H., Qin, G., He, C., Li, B., and Tian, S. 2016. The MADSBox transcription factor Bcmads1 is required for growth, sclerotia production and pathogenicity of Botrytis cinerea. Sci. Rep. 6:33901.

Zhao, Z., Liu, H., Wang, C., and Xu, J. R. 2013. Comparative analysis of fungal genomes reveals different plant cell wall degrading capacity in fungi. BMC Genomics 14:274.

Zheng, Z., Gao, T., Zhang, Y., Hou, Y., Wang, J., and Zhou, M. 2014. FgFim, a key protein regulating resistance to the fungicide JS399-19, asexual and sexual development, stress responses and virulence in Fusarium graminearum. Mol. Plant Pathol. 15:488-499. 